\title{
OS DETERMINANTES DOS RESULTADOS DE SOMA POSITIVA EM MINAS GERAIS E NO RIO GRANDE DO SUL
}

\author{
Felipe Nunes
}

\begin{abstract}
RESUMO
O artigo trada dos processos decisórios no âmbito dos estados de Minas Gerais e Rio Grande do Sul entre 1999 e 2006. Pretende-se ampliar a abrangência dos estudos sobre os poderes estaduais no Brasil focando nos poderes legislativos considerados mais desenvolvidos institucionalmente. O argumento geral é que resultados de soma positiva não são obtidos de maneira espontânea, mas construídos a partir de negociação entre os governantes. Nessa direção, afirma-se que a dinâmica dos governos subnacionais brasileiros não segue uma constante de ultrapresidencialismo: há variação no tipo de relacionamento entre Executivo e Legislativo e entre governo e oposições, a depender do nível de desenvolvimento institucional e do grau de estruturação dos subsistemas partidários. Os resultados mostram que essa variação é ainda mais forte a depender do tipo de coalizão governativa. Vale destacar, primeiro, que o tipo de coalizão composta depende de características do subsistema partidário. Em segundo lugar, que quanto mais coalescente uma coalizão de governo, e quanto mais contígua uma coalizão de governo, menor é o volume de resultados de soma positiva obtidos por um governo.
\end{abstract}

PALAVRAS-CHAVE: legislativos estaduais; executivos estaduais; sucesso legislativo; coalizões governativas; soma positiva.

\section{INTRODUÇÃO ${ }^{1}$}

Por que os governos são bem sucedidos na produção de resultados legislativos não-conflitivos? $\mathrm{Ou}$, ainda, de que maneiras as estratégias de formação de coalizões utilizadas pelos governadores afetam o apoio dos deputados estaduais aos projetos de autoria do governo, implicando um maior número de legislação não-conflitiva no Legislativo? Essas são as questões que serão respondidas neste artigo. De maneira geral, o que se procura conhecer é o modo como variadas estratégias $(i)$ de formação de maiorias e (ii) de cooptação, atração ou satisfação de interesses de minorias e/ou oposições podem resultar em diferentes formas de apoio Legislativo ao governo estadual. Esse é um debate que já foi extensivamente elaborado para

\footnotetext{
1 Este artigo foi elaborado a partir da dissertação de mestrado "Governos de Coalizão e Resultados de Soma Positiva em Minas Gerais e no Rio Grande do Sul 1999-2006" apresentada como requisito parcial para obtenção do título de Mestre em Ciência Política na Universidade Federal de Minas Gerais (UFMG). Agradeço enormemente aos comentários das minhas orientadoras, Fátima Anastasia e Monica Mata Machado de Castro, e dos membros da banca avaliadora, Magna Inácio e Octavio Amorim Neto. Agradeço também aos dois pareceristas anônimos da Revista de Sociologia e Política. O trabalho foi integralmente financiado por bolsa de pesquisa da Fundação de Amparo à Pesquisa do Estado de Minas Gerais (Fapemig), concedida entre 2007 e 2008.
}

o nível nacional (LIMONGI \& FIGUEIREDO, 1994; SANTOS, 1997; 2003; LIMONGI, 2006), mas que ainda carece de atenção para o nível subnacional de governo.

A diferença, no entanto, é que este trabalho analisa a produção de decisões nos estados brasileiros sob a óptica da obtenção de resultados de soma positiva: resultados que não impõem custos concentrados para nenhum dos atores em competição. Mas por que interessa explicar os resultados de soma positiva? Porque a maioria dos analistas acredita que o motor das ações dos governantes é a aprovação da agenda do governo, sendo que as vitórias, assim com as derrotas, podem dar-se em contextos muito diferentes. Acredita-se que a soma de derrotas e vitórias não deve ser feita pelo computo de quanto foi aprovado ou rejeitado, mas, também, de como essas vitórias e derrotas foram obtidas. Argumenta-se que é na repercussão pública das medidas adotadas pelo governo que se deveria mensurar o sucesso do Executivo em implementar sua agenda. De que adianta aprovar uma lei se o Executivo não pode reclamar crédito político pela mesma quando a opinião pública foi exposta às vicissitudes do processo que se desencadeou nessa aprovação?

Pretende-se contribuir para a compreensão dos processos decisórios no âmbito dos estados no período posterior à redemocratização (desde 1988), discutindo 
os fatores que incentivam os deputados estaduais, reunidos em bancadas partidárias, juntamente com o Executivo, a conduzir a agenda política em pauta. Nesse sentido, o trabalho insere-se no debate acerca do "governismo"2 (ABRÚCIO, 1998; 2002; ANDRADE, 1998; COUTO, 1998; SANTOS, 2001) sob governos presidencialistas unicamerais, na tentativa de qualificar tal padrão que, segundo Abrúcio, Teixeira e Costa (2001), é encontrado "em quase todos os deputados estaduais" estudados por ele no Brasil. O objetivo aqui traçado é o de qualificar a ideia do governismo, por meio da discussão crítica da tese do "ultrapresidencialismo". Seria tal conceito a expressão de uma tese ultrapassada?

Este artigo foi desenvolvido tendo como corte temporal o período de 1999 a 2006 em dois legislativos estaduais brasileiros, a saber: a Assembléia Legislativa de Minas Gerais (ALMG) e a Assembléia Legislativa do Rio Grande do Sul (ALRS). Dentro do período supracitado, os dois casos são considerados os mais desenvolvidos institucionalmente no Brasil (SANTOS, 1997) e, portanto, trata-se do desenho de pesquisa mais adequado para se testar os mecanismos em operação dentro desse contexto e que determinam a capacidade do Legislativo 'enfrentar' o Executivo. O posicionamento ideológico dos governadores, a dinâmica político-partidária dos estados e os tipos de governos formatados, que variam significativamente nesses dois estados e que são tidos como os principais determinantes do sucesso legislativo dos presidentes, serão mobilizados para explicar as diferenças e as variações aferidas na produção de resultados de soma positiva nos estados.

É evidente a necessidade de estudos mais densos e sistemáticos para o conhecimento da realidade subnacional. O grande desafio a ser enfrentado parece o da elaboração de modelos explicativos multivariados que deem conta dos padrões empíricos observados. Para tanto, o desenho de pesquisa comparativa, como a que é proposta aqui, parece ser a melhor estratégia. Como lembrado por Anastasia (2001, p. 67), “os padrões encontrados de interação entre Executivo e Legislativo no âmbito estadual não autorizam, sem mais, a reiteração da hipótese do "ultrapresidencialismo estadual'. Tais padrões não autorizam, ademais, a desconsideração das diferenças e das diversidades que atravessam esse conjunto de instituições, as quais

2 Segundo Abrúcio (1998), "governismo" pode ser definido como o padrão de atuação dos deputados que, formal ou informalmente participando da bancada do governo, votam com o Executivo, visto que eles não podem sobreviver politicamente sem usufruir dos recursos do Executivo. poderiam ser encontradas através de uma análise mais aprofundada". Anastasia (idem) torna clara, ao tratar dos poderes Executivo e Legislativo no âmbito dos estados da federação, a diversidade institucional encontrada nos legislativos subnacionais e, com isso, recoloca o desafio lançado por Lima Jr. (1983) de compreender o funcionamento dos subsistemas políticos estaduais.

$\mathrm{O}$ artigo está organizado em três seções. $\mathrm{Na}$ primeiro, apresenta-se o sucesso legislativo dos governadores de Minas Gerais e Rio Grande do Sul propondo-se a construção de um indicador de sucesso que supere algumas das debilidades apontadas na literatura a respeito dos indicadores comumente utilizados. No segundo, passa-se à descrição e análise da lógica de funcionamento das coalizões legislativas nos dois estados. Mostra-se que não é a cooptação e o governismo que definem o legislador estadual. Por fim, hipóteses são testadas acerca da relação entre a composição de coalizões governativas por meio da distribuição de cargos políticos e obtenção de resultados de soma positiva.

\section{SUCESSO LEGISLATIVO}

Boa parte do debate contemporâneo na área de estudos legislativos foca a atenção sobre o grau de sucesso (ou de fracasso) na aprovação de uma determinada agenda governamental e sobre os principais fatores responsáveis pelas variações desse fenômeno ${ }^{3}$. Embora haja um extenso debate sobre o tema aplicado aos casos nacionais, interpretações complementares, que se concentrem nos estados da federação, ainda parecem possíveis. Nesta seção analisa-se a taxa de sucesso legislativo dos governos estaduais de Minas Gerais e Rio Grande do Sul entre 1999 e 2006, com ênfase no processo legislativo nos dois estados. $\mathrm{O}$ argumento aqui desenvolvido é que, em primeiro lugar, para analisar o sucesso legislativo de um determinado governo deve-se considerar, também, a dinâmica

\footnotetext{
3 Não faz parte dos objetivos deste trabalho discutir o pressuposto que está por trás da noção de estabilidade e governabilidade em democracias presidencialistas. No entanto, vale anunciar o ponto de divergência entre a perspectiva que se pretende desenvolver e a que é comumente trabalhada pela literatura especializada. Tendo em vista os objetivos de um sistema democrático, acredita-se impertinente o desejo normativo que sustenta a afirmação de que o presidente deve aprovar sua agenda. Essa afirmação, fortemente influenciada por princípios majoritários, esquece que o presidente, embora seja o principal ator de um governo, não é o único relevante. Além de seus interesses, há muitos outros que precisam ser incorporados à agenda política por serem a expressão dos anseios de parte, algumas vezes considerável, de cidadãos de determinado país. Para uma visão geral sobre a produção teórica nessa área no Brasil, ver Santos (2001).
} 
política resultante do embate entre os atores em competição. Além disso, para distinguir a natureza e o escopo da agenda aprovada pelos governos e, consequentemente, extrair daí implicações sobre o grau de poder desses atores, faz-se necessário incluir, na noção de sucesso, as possibilidades estratégicas de ação e bloqueio à disposição dos atores, sobretudo durante o processo de tomada de decisão.

O debate sobre os mecanismos causais que levariam ao sucesso legislativo contrapõe duas importantes vertentes analíticas: $(i)$ a primeira resulta dos argumentos e proposições teóricas do trabalho seminal de Neustadt (1960) e enfatiza como variáveis explicativas as habilidades pessoais daquele que ocupa o principal cargo do Executivo, a Presidência da República; (ii) a segunda vertente chama atenção para as instituições e as estruturas políticas como as principais responsáveis pelo maior ou menor grau de aprovação da agenda de um governo (BOND \& FLEISCHER, 1990; PETERSON, 1993; JONES, 1994; CAMERON, 2000). Partindo de pressupostos e argumentos distintos, ambas reconhecem que o sucesso legislativo do Executivo depende de algum mecanismo de negociação que ocorre, principalmente, durante a tramitação dos projetos no Legislativo.

Há um ponto de convergência entre as duas vertentes que necessita de análise mais sistemática por realçar o ponto central da obtenção do sucesso: o processo de negociação para obtenção de acordos políticos entre os diversos atores em competição. $\mathrm{Na}$ visão do chefe do Executivo, tão importante quanto obter uma vitória no Legislativo é conduzir bem essa vitória $^{4}$. A condução da agenda de governo de forma eficaz está associada aos resultados que apresentam baixos custos políticos na relação com o Legislativo e, mais particularmente, na relação com a oposição ${ }^{5}$. Isso se dá tanto porque as repercussões de disputas com altos custos podem ser negativas e ter impacto sobre a avaliação que os eleitores farão do trabalho do governo $^{6}$ (GROSECOLE \& MCCARTY, 2001), como

\footnotetext{
4 A análise dos mecanismos causais da variação no sucesso legislativo dos governadores será tratada de forma detida na segunda seção deste artigo.

5 Na visão apresentada nesta seção, mais do que analisar a relação entre os poderes, Executivo e Legislativo, busca-se entender a dinâmica da competição entre governo e oposição. Como será desenvolvido mais adiante, não se enfatiza a existência de conflitos entre os poderes, mas a disputa entre os "lados" diferentes, ou seja, daqueles que compõem o governo e a oposição.

6 O pressuposto em que se baseia tal assertiva é o de que os atores políticos têm como objetivo maximizar sua permanência na política. Se não for buscando sua reeleição, será almejando outro cargo político (eletivo ou não).
}

porque o sistema político arquitetado no Brasil gera incentivos para que adversários do passado possam vir a ser aliados no futuro ${ }^{7}$. Se a avaliação do sucesso legislativo de um governo não depende apenas do resultado final das matérias, mas também do processo que leva a ele, então o foco analítico deve recair sobre o processo de produção legislativa expresso nos procedimentos escolhidos para a tomada de decisão. Acredita-se possível classificar o tipo de resultado obtido pela forma como uma decisão é tomada.

A questão que se coloca, então, é como avaliar o desempenho do governo com referência à condução da agenda política. Para julgar o desempenho dos governos norte-americanos, os analistas consideram, em geral, indicadores de sucesso legislativo focados no início e no final da tramitação de cada matéria. Há três medidas propostas. A primeira considera o número das votações nominais em matérias sobre as quais a Presidência toma posição ${ }^{8}$. A segunda mede a proporção de projetos com o apoio do presidente que foram aprovados em um determinado período. A terceira trata do tamanho, da consistência e da durabilidade do apoio de cada parlamentar ou grupo de parlamentares aos projetos de interesse do governo.

É consenso na literatura que as tentativas de medir o sucesso legislativo, embora promissoras, devem ser aprimoradas (SAIEGH, 2011). O primeiro indicador citado apresenta, na visão de Jones (1994), problemas para a avaliação do desempenho presidencial, já que não considera $(i)$ os projetos votados simbolicamente, (ii) os rejeitados ou (iii) os não apreciados nas comissões. $\mathrm{O}$ autor critica ainda o fato de que as votações nominais, em geral, referem-se a temas específicos da pauta de discussões. O segundo indicador é criticado por não considerar a importância ou o peso que cada matéria tem para a agenda e, como consequência, sobrestima ou subestima o sucesso obtido. O terceiro, por sua vez, desconsidera a estratégia abstencionista usada por parlamentares como forma de evitar os custos de assumir uma determinada posição publicamente (COHEN \& NOLL, 1991). É a falta de uma medida intermediária que supere esses

\footnotetext{
7 Refere-se aqui ao multipartidarismo associado à representação proporcional de lista aberta que dificultam a formação de governos majoritários nas urnas, levando os atores políticos a associarem-se na composição de um governo multipartidário.

8 Vale ressaltar que os presidentes americanos não podem iniciar diretamente matérias no Legislativo. Por isso, o método utilizado para medir o sucesso só considera as matérias em que o presidente se pronuncia publicamente. Diferentemente dos EUA, os presidentes brasileiros não só podem iniciar legislação, como tem exclusividade de iniciativa legislativa em áreas como orçamento público.
} 
problemas que motiva a seção seguinte do texto.

\section{ASSEMBLEIAS LEGISLATIVAS COMO SISTE- MAS DE COMITÊS}

Sartori (1994) define um comitê como um grupo pequeno de interação face a face, durável e institucionalizado, que gera resultados em relação a um fluxo de decisões. Ao elaborar essa proposição, Sartori abre espaço para que seja proposto um entendimento particular do funcionamento de assembleias legislativas. De maneira objetiva, o que se está propondo é que os legislativos subnacionais sejam compreendidos como sistemas de comitês: um corpo de parlamentares com preferências intensas distintas que tem como característica predominante tomar decisões em que todos os participantes podem ganhar. $\mathrm{O}$ que se está postulando aqui é que os legislativos estaduais podem ser analisados como organizações tipicamente de comitês, nas quais o mecanismo do acordo opera na maior parte das decisões. No interior de um parlamento, além de votar, os deputados buscam acordos em torno das matérias em pauta.

Os legislativos brasileiros são duráveis, institucionalizados e tomam decisões em fluxo contínuo. Talvez, os únicos critérios que não se encaixem perfeitamente à definição sartoriana de comitês sejam os $(i)$ do tamanho e (ii) do modo de decidir. Quanto ao tamanho, é fácil argumentar que casas legislativas subnacionais são pequenas e funcionam de acordo com os critérios de Sartori (idem). Quanto ao modo de decidir, ainda segundo Sartori, nos comitês as decisões em geral não são postas em votação. Quando são, o voto costuma ser pro forma, na maior parte das vezes, as decisões são unânimes. E é exatamente isso o que se observa nos dois casos analisados aqui. Em Minas Gerais o número de decisões tomadas por meio de votações nominais, entre 1995 e 2006, não passou de 190, em um total de cerca de 20000 proposições - entre Projetos de Lei, Projetos de Lei Complementar, Projetos de Emenda Constitucional e Requerimentos. No Rio Grande do Sul, entre 2000 e 2006, ocorreram no Rio Grande do Sul 2836 votações nominais, mas dessas apenas $24,7 \%$ tiveram menos de $80 \%$ da casa votando de forma convergente. Isso indica que, mesmo decidindo por votação nominal, na maioria das votações o resultado final é obtido com o acordo da quase a totalidade dos 55 deputados.

Parece, então, ser possível sustentar que o funcionamento desses dois legislativos subnacionais segue o padrão observado no que Sartori definiu como um "sistema de comitês". De onde pode-se deduzir que as decisões tomadas são, majoritariamente, de soma positiva. Dada a "disposição negociadora" permitida por intensidades desiguais, os comitês sustentam suas decisões por meio da projeção dos retornos futuros aos seus membros. Seria ingênuo, no entanto, acreditar que não há conflitos nessas instituições. Provavelmente, nenhuma harmonia preestabelecida preside a distribuição de preferências e é raro que os ganhos sejam distribuídos por igual. Como salienta Sartori (idem, p. 307), às vezes, "também os comitês têm de por as cartas na mesa, isto é, têm realmente de decidir por um voto majoritário".

Se os legislativos subnacionais podem ser interpretados como sistemas que têm uma maneira de chegar a decisões semelhante à de um comitê, interessa analisar as proposições que dão origem a resultados de soma positiva onde o governo apresenta suas preferências, e o legislativo, por meio de vetos garantidos regimentalmente, protege as preferências que representa. Nessa interpretação, as regras de tomada de decisão são fundamentais. $\mathrm{O}$ fato de o Legislativo eleger regras de maioria qualificada, simples, ou absoluta faz toda a diferença na avaliação de qual foi o resultado obtido. Ao garantir os direitos da minoria, o Legislativo permite que os resultados sejam favoráveis ao governo e, ao mesmo tempo, não desfavoráveis para a oposição - o que caracterizaria o jogo de soma positiva no processo decisório.

Tendo como base esse modelo teórico, define-se aqui que o sucesso legislativo do governo nos estados é medido a partir do número de matérias em que o Executivo chega a uma decisão (aprovação ou não) sem que o mecanismo da regra da maioria seja acionado. A definição arquiteta-se, assim, porque as decisões por regra majoritária dão origem a resultados de soma zero, o que pode comprometer a estratégia aninhada que o governador possa ter em termos de sua carreira política, de médio ou longo prazo. Quanto mais se aprova sem a necessidade de uso de votações nominais, maior é o sucesso legislativo de soma positiva do governador.

A partir desses supostos, propõe-se, então, que a análise do grau de sucesso dos governos subnacionais seja feita a partir da análise dos procedimentos utilizados para a produção de decisões coletivas. $\mathrm{Ou}$ seja, é a interação entre procedimentos e resultados que vai informar qual é o tipo de decisão produzida. São seis as interações possíveis de serem observadas: (i) decisões internas às comissões; (ii) decisões por votações simbólicas; (iii) decisões por votações nominais obrigatórias sem conflito; (iv) decisões por votações nominais requeridas sem conflito; $(v)$ decisões por votações nominais obrigatórias com conflito; (vi) decisões por votações nominais requeridas com conflito.

A partir dos pressupostos apresentados, os quatro 
primeiros tipos de decisões darão origem a resultados de soma positiva: todas as decisões se dão por meio de acordos expressos nos resultados aferidos. As decisões 5 e 6 , ao contrário, serão classificadas como as que dão origem a resultados de soma zero, pois apenas o escrutínio individual no plenário foi capaz de encerrar o conflito apresentado naquela matéria. Observe-se que não interessa se tratam de proposições aprovadas ou rejeitadas, mas da forma como o resultado é obtido. Isso é importante para o argumento aqui defendido, porque se está analisando a relação entre poderes e entre posições políticas, valorizando o papel do debate e da negociação no jogo político. É nesse sentido que se defende que as arenas eleitorais e legislativas combinam-se. Afinal, uma proposta não aceita no legislativo pode expressar a rejeição daquela matéria para o conjunto de interesses representados no parlamento. Isso não é insucesso de um governo, mas a prova de que decisões são produzidas por meio da interação de atores que competem por issues que interessam aos seus representados.

Para ter-se uma noção melhor do que se está propondo, apresentam-se, a seguir, os resultados da taxa de sucesso legislativo - utilizando-se o indicador tradicional de produção legislativa apresentado e criticado anteriormente - e da taxa de resultados de soma positiva dos governadores de Minas Gerais (MG) e Rio Grande do Sul (RS) entre 1999 e 2006. Considerando apenas os Projetos de Lei, os Projetos de Emenda Constitucional e os Projetos de Lei Complementar ${ }^{9}$, observa-se que, de 1999 a 2006, o Executivo de MG é responsável por 9,1\% (590 de 6 516) das proposições apresentadas. No RS esse percentual chega a 31\% (919 de 2968 ). Já é possível afirmar que o Legislativo apresenta mais proposições do que o governador. A seguir, é possível observar a comparação dos resultados das duas medidas. A reclassificação do sucesso legislativo dos governos estaduais, como proposta neste trabalho, revela que a forma como as decisões são tomadas nos estados não pode ser desconsiderada ${ }^{10}$.

\footnotetext{
${ }^{9}$ As demais proposições não serão analisadas porque não comprometem parte substantiva da agenda do governo. As proposições como convênios, requerimentos e projetos de resolução são, na interpretação da literatura especializada, pouco expressivos e significativos dos interesses mais proeminentes do governo.

10 Todos os PL, PLC e PEC entre 1999 e 2006 apresentados pelo Executivo e que tiveram a chance de ser analisados pelo plenário foram examinados. Os projetos foram classificados como de soma zero se houve uma votação nominal (regimental ou não) conflituosa. O restante foi considerado como de soma positiva; exceto as matérias em tramitação, arquivadas ou anexadas que não foram analisadas.
}

TABELA 1 - GRAU DE SUCESSO DOS GOVERNADORES NOS ESTADOS, MG E RS (MEDIDA TRADICIONAL) (1999-2006) (\%)

\begin{tabular}{|l|c|c|}
\hline & RS & MG \\
\hline Aprovado & 85,4 & 72 \\
Rejeitado & 14,6 & 28 \\
Total & 100 & 100 \\
& $(919)$ & $(590)$ \\
\hline
\end{tabular}

FONTE: O autor, a partir do banco de dados de produção legislativa (MG e RS) (NUNES, 2009b).

Com a utilização do indicador tradicional, os governadores mineiros são classificados, entre 1999 e 2006, como obtendo $72 \%$ de vitórias. O indicador aqui proposto mostra que, das decisões tomadas em Minas, 98\% geram resultados de soma positiva. No caso do Rio Grande do Sul, das decisões produzidas, 93\% deram origem a resultados de soma positiva, mesmo considerando a mudança regimental ocorrida no estado, em 2003, obrigando que todas as decisões se dessem por votações nominais.

TABELA 2 - GRAU DE SUCESSO DOS GOVERNOS ESTADUAIS, MG E RS (MEDIDA PROPOSTA) (19992006) (\%)

\begin{tabular}{|l|c|c|}
\hline & RS & MG \\
\hline Soma Zero & 6,8 & 2,3 \\
Soma Positiva & 93,2 & 97,7 \\
Total & 100 & 100 \\
& $(810)$ & $(430)$ \\
\hline
\end{tabular}

FONTE: O autor, a partir do banco de dados de produção legislativa (MG e RS) (NUNES, 2009b).

NOTA: Algumas propostas não apresentam informação completa para que sejam classificadas como soma zero ou positiva, por isso o total nas tabelas 1 e 2 são diferentes

O que chama atenção nesses resultados é a possibilidade de caracterizar-se a produção legislativa das assembleias de Minas Gerais e Rio Grande do Sul como processos que tem como resultado decisões por soma positiva. Vale lembrar que um resultado de soma positiva, como aqui entendido, pode ser, inclusive, uma matéria rejeitada. Se a aprovação de matérias parece alta nos dois casos analisados, a observação de que os resultados de soma positiva são maiores ainda trazem indagações sobre por que em tais estados opta-se por esse tipo de decisão. Apesar das diferenças intrínsecas aos dois casos, o padrão encontrado entre eles é muito semelhante. Ou seja, ao desagregar o conjunto de 
proposições apresentadas pelo Executivo e tramitadas na Assembleia, encontramos um padrão de decisão tipicamente cooperativo. A grande maioria das matérias aprovadas e/ou rejeitadas no Legislativo foi decidida por meio de procedimentos que incentivam sucessos não-conflituosos.

Pensando na estratégia adotada pela literatura para analisar a produção nos legislativos e os resultados até aqui obtidos, parece possível afirmar que o conflito evidenciado no plano nacional é marginal nos estados analisados, quando se adota, como estratégia de análise, a classificação do sucesso legislativo do governo tendo como referência os resultados de soma positiva. Se for replicada a estratégia de pesquisa adotada no plano nacional para o estudo dos casos estaduais, corre-se o risco de não se evidenciar que a maioria das decisões ocorre, de fato, pela utilização de votações simbólicas ou de decisões nas comissões com poder terminativo. Ou ainda, pode-se aventar a hipótese de que as decisões que chegam ao plenário sem acordo, ou sem consenso, resultam de ineficiência do governo para discutir e negociar com os legisladores uma forma de atender às demandas dos interesses ali representados.

TABELA 3 - GRAU DE SUCESSO NOS ESTADOS POR GOVERNO, MG E RS (MEDIDA TRADICIONAL) (19992006) (\%)

\begin{tabular}{|l|c|c|c|c|}
\hline & Dutra & Rigotto & Itamar & Aécio \\
\hline Aprovado & 77,7 & 90,5 & 67,2 & 74,3 \\
Rejeitado & 22,3 & 9,5 & 32,8 & 25,7 \\
Total & 100 & 100 & 100 & 100 \\
& $(363)$ & $(556)$ & $(189)$ & $(401)$ \\
\hline
\end{tabular}

FONTE: O autor, a partir do banco de dados de produção legislativa (MG e RS) (NUNES, 2009b).

Considerando as informações por governo, os resultados são os seguintes: em MG o Governador Itamar Franco (PMDB) aprova 67,2\% das propostas que apresenta e o Governador Aécio Neves (PSDB) aprova 74,3\%. No RS o Governador Olívio Dutra (PT) obteve vitória em $77,7 \%$ das proposições apresentadas, e o Governador Germano Rigotto, 90,5\%.
TABELA 4 - GRAU DE SUCESSO NOS ESTADOS POR GOVERNO, MG E RS (MEDIDAPROPOSTA) (1999-2006) $(\%)$

\begin{tabular}{|lccccc|}
\hline & Dutra & Rigotto & Itamar & Aécio \\
\hline Soma Zero & 0 & 10,7 & 6,2 & 0,7 \\
Soma & 100 & 89,3 & 93,8 & 99,3 \\
Positiva & & & & \\
Total & 100 & 100 & 100 & 100 \\
& $(294)$ & $(516)$ & $(130)$ & $(300)$ \\
\hline
\end{tabular}

FONTE: O autor, a partir do banco de dados de produção legislativa (MG e RS) (NUNES, 2009b).

NOTA: Algumas propostas não apresentam informação completa para que sejam classificadas como soma zero ou positiva, por isso o total nas tabelas 3 e 4 são diferentes.

Os dados desagregados por governo também revelam que a reclassificação do grau de sucesso torna mais clara a análise do padrão de relacionamento com o legislativo, estabelecido pelos governadores. O que chama atenção é que os governos Dutra (PT) e Aécio (PSDB) não produzem resultados de soma zero, enquanto Rigotto e Itamar, ambos do PMDB, apresentam cerca de $10 \%$ de decisões desse tipo. O caso do Rio Grande do Sul merece destaque, pois os padrões encontrados são completamente distintos. Enquanto o governo do PT não produz nenhum resultado de soma zero, o governo do PMDB convive com a maior taxa de resultados desse tipo entre os casos aqui comparados. Novos estudos comparados poderão indicar se esse padrão é replicado em outros estados e quão distante são esses resultados do resto do país. Mas o fato é que a variação entre e dentro dos estados merece atenção e precisa ser explicada.

A predominância dos resultados de soma positiva só foi identificada pela desagregação do sucesso legislativo em categorias que determinam se os resultados obtidos são de soma zero ou soma positiva. Se utilizando o indicador tradicional, o agregado de aprovações não permitia indicar a forma como a decisão foi tomada. Ao medir-se o sucesso legislativo com a preocupação de distinguir os resultados de soma positiva dos de soma zero, chega-se a um padrão mais claro de tipificação das proposições.

Vale, por fim, observar se a aprovação das matérias está relacionada ao padrão decisório estabelecido nos casos analisados. No gráfico abaixo é possível observar a relação entre tipo de resultado e aprovação. Embora a diferença entre matérias aprovadas e rejeitadas seja muito grande, é interessante notar que, entre as matérias aprovadas, a maioria é de soma positiva, enquanto entre as matérias rejeitadas a diferença não é estatisticamente 
significativa. Esses resultados podem fornecer algumas pistas para se explicar o elevado grau de aprovação das decisões. As questões que chegam ao plenário sem acordo necessitam do embate pelo voto individual e são decididas de maneira conflituosa, e podem ser rejeitadas pelo Legislativo. Talvez porque o governo não tenha sido capaz de "ir ao plenário" e discutir com os partidos a política que melhor atenda aos interesses dos legisladores, talvez porque o governo não tenha arquitetado uma coalizão suficientemente coordenada que seja capaz de tomar as decisões voltadas para seus interesses.

\section{GRÁFICO 1 - PROPORÇÃO DE MATÉRIAS APROVADAS E REJEITADAS POR TIPO DE RESULTADO}
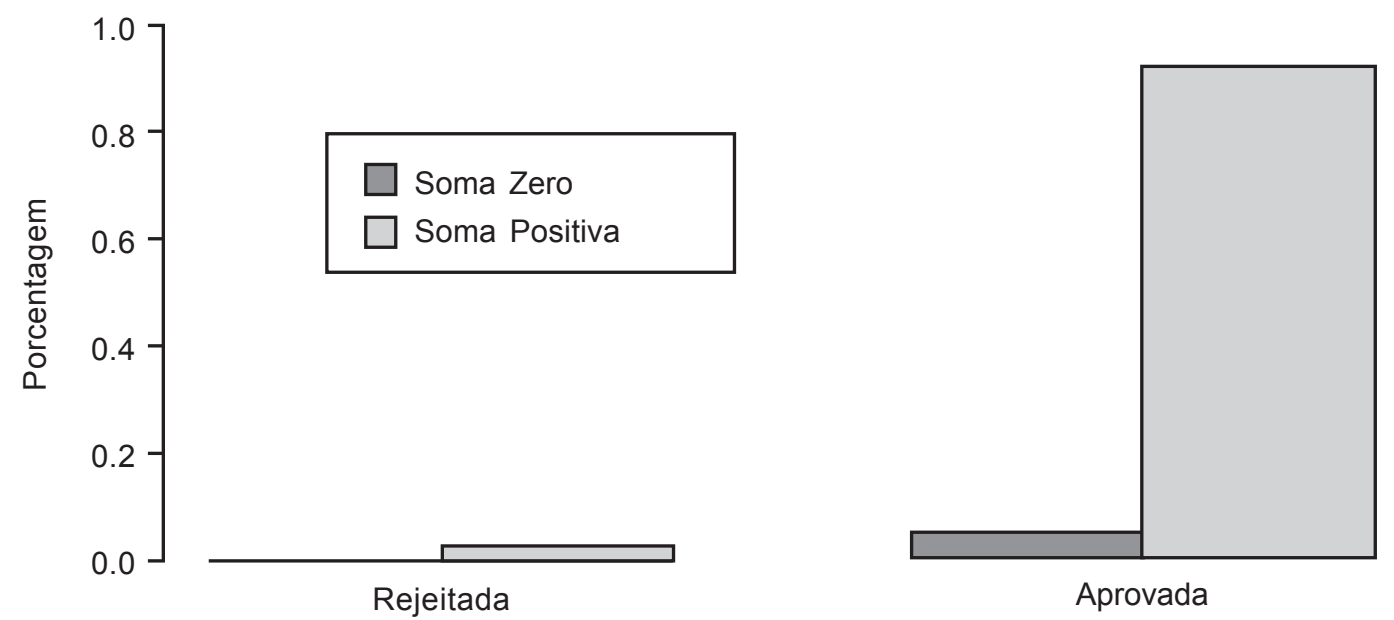

Status da Matéria

FONTE: O autor, a partir do banco de dados de produção legislativa (MG e RS) (NUNES, 2009b).

Se a comparação é feita entre os governos (Gráfico 2), evidencia-se o fato de que a aprovação, no governo Rigotto, diferentemente do restante dos casos, tenha como característica principal os resultados de soma zero. Será valioso conhecer a forma como esse governador lidava com os recursos a sua disposição, para identificar o efeito da utilização estratégica desses recursos nesses resultados.

\section{GRÁFICO 2 - PROPORÇÃO DE MATÉRIAS APROVADAS POR TIPO DE RESULTADO E POR GOVERNO}

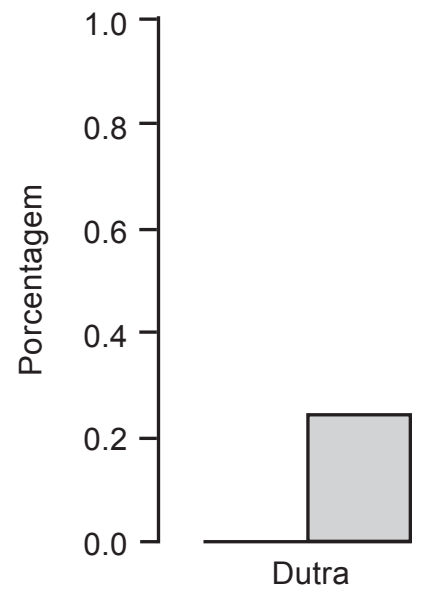

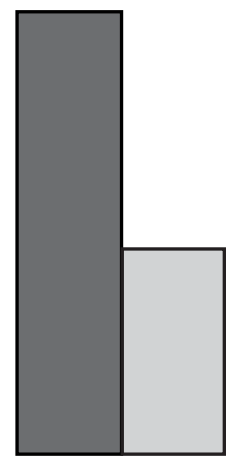

Rigotto

Soma Zero

Soma Positiva

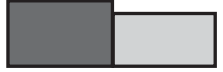

Itamar

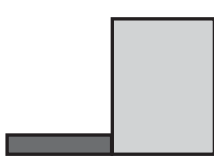

Aécio

Governos Estaduais

FONTE: O autor, a partir do banco de dados de produção legislativa (MG e RS) (NUNES, 2009b). 
Se a variação aqui observada exige uma reflexão sobre o que, em termos de ações de governo, leva a padrões distintos de governabilidade, parece razoável afirmar que desagregar o indicador de sucesso tradicional nas duas categorias supracitadas, leva a análise do sucesso legislativo dos governos estaduais a resultados mais sensíveis em termos do padrão de relacionamento entre governo e oposição, entre os dois poderes e no que concerne à dinâmica no interior do Legislativo. Os dados deixam claro que há padrões diferentes de resultados ao longo do tempo e entre os estados. Sendo assim, o esforço a partir de agora é o de identificar os nexos que conectam meios (estratégia de governo) a fins (sucesso legislativo) sob a óptica dos Governadores.

\section{SOMA POSITIVA, COALIZÕES DE GOVERNO E GABINETES DE COALIZÃO}

Como mostrado por Nunes (2011) para os casos de Minas Gerais e Rio Grande do Sul, após a redemocratização, os governos compõem coalizões governativas baseadas em acordos partidários e preferem chegar a consensos e a acordos que transpassam o Executivo e o Legislativo. O padrão de formação de coalizões começa nas eleições e estendese por todo o período de governo. Observa-se que negociações dão-se dentro do governo e contam com a colaboração de quem está fora dele; barganhas tomam vida e envolvem aliados do presente com os possíveis aliados do futuro. Esses acordos são construídos por meio dos partidos no Legislativo, e embora haja divergência de preferências, há certa sistematicidade na forma como cada coalizão é arquitetada. Nesta seção, pretende-se apresentar resultados que mostrem como o padrão de formação de coalizões partidárias impacta na produção de resultados de soma positiva em Minas e no Rio Grand do Sul.

Se Cheibub, Przeworski e Saiegh (2004) estão corretos ao afirmar que "coalizões ministeriais formamse quando a distância política entre o principal partido da coalizão (formateur) e o partido dele mais próximo é relativamente grande" (idem, p. 576), então, a disposição para negociar políticas varia inversamente à distância observada entre os partidos. Considerando que, em sistemas presidencialistas, o acesso aos cargos do governo significa acesso a poder, então a divisão do poder político conquistado pelo chefe do Executivo só se justifica se aquele que está recebendo poder abre mão de algo relevante para quem está oferecendo os recursos. $\mathrm{O}$ argumento dos autores acima é que quanto mais distantes estiverem as preferências do Executivo e do partido com o qual se está negociando, maior tende a ser a negociação por cargos, em troca da aprovação da política preferida pelo governo.
A partir desse raciocínio, parece plausível pensar que a distribuição coalescente dos cargos nas secretarias acontece quando os atores em negociação não concordam com a agenda proposta e, assim, fazse necessário trocar poder político - por meio de cargos - para dar origem aos resultados desejados por aquele que detinha acesso privilegiado aos recursos. Nesse contexto, ao fim e ao cabo, decisões com menor grau de consenso entre os atores em competição serão enviadas pelo Executivo para tramitação no Legislativo. Sendo assim, é de se esperar que decisões de soma zero sejam mais recorrentes, de onde propõe-se que: Hipótese 1: quanto mais coalescente uma coalizão de governo, menor será o volume de decisões que levam a resultados de soma positiva.

$\mathrm{O}$ argumento da atratividade das coalizões (INÁCIO, 2006), associado ao da proximidade das preferências dos atores em negociação (CHEIBUB, PRZEWORSKI \& SAIEGH, 2004), fundamenta a ideia exposta na hipótese dois: quanto mais contigua uma coalizão de governo, menor será o volume de decisões que levam a resultados de soma positiva.

Afinal, quanto mais próximos os atores em competição mais fácil tende a ser a aceitação de uma política comum, o que cria a possibilidade de que se prefiram decisões tomadas por meio de procedimentos que favoreçam resultados de soma zero. Se essas conclusões puderem ser encontradas também no nível subnacional, a dimensão ideológica terá que ser reconsiderada nos estudos sobre governabilidade.

Embora muitos afirmem a inexistência de partidos fortes no Brasil (MAINWARING, 1993), sobretudo no nível subnacional (LIMA JR., 1997), resultados de pesquisas recentes, realizadas no âmbito dos estados, mostram que o posicionamento ideológico dos partidos segue tendência semelhante à observada nacionalmente (CASTRO, ANASTASIA \& NUNES, 2009), e que os partidos são lembrados como os mais importantes interlocutores com os governos estaduais no momento de composição de coalizões (NUNES, 2012).

Além disso, como argumenta Mair (2006) os partidos tornaram- se mais fracos na arena eleitoral, mas fortaleceram-se na arena parlamentar. Esse fortalecimento no Legislativo fez com que as grandes organizações partidárias tendessem a reforçar sua estrutura interna, dando mais capacidade aos líderes partidários para coordenar suas legendas. Esse paradoxo, do enfraquecimento versus fortalecimento em distintas arenas, acabou levando os analistas a isolar os efeitos cruzados entre o funcionamento dos partidos no interior dos parlamentos e a conexão eleitoral. Parece ser plausível afirmar que a força legislativa das agremiações tem sido definidora a partir da observação 
da operação efetiva de coalizões governativas em presidencialismos. Embora a força da ideologia no processo de formação de governos não tenha sido o foco da discussão de Figueiredo e Limongi (1999), ao analisar o caso brasileiro posterior à redemocratização, os autores parecem ter resultados sólidos para argumentar que os partidos importam.

Por fim, propõe-se que: H3: quanto maior o contingente legislativo de um governo, menor será o volume de decisões que levam a resultados de soma positiva.

A hipótese três é justificada pela lógica que conecta os custos e os benefícios de um processo de tomada de decisão em contextos democráticos. Considerando que o critério básico que define as decisões políticas nesses arranjos é a regra da maioria - seja ela absoluta, seja qualificada - então a propensão a observância de acordos será tanto menor quanto menor for a incerteza de que uma maioria legislativa está assegurada. Se a disciplina é alta e o contingente controlado pelos governos é suficiente para lhes garantir aprovações sem custos decisórios, então, a tendência é de que se opte com mais frequência por decisões de soma zero ${ }^{11}$. Dito de outra forma, como os legislativos adotam a regra da maioria como procedimento para solução de impasses políticos, então tanto mais vantajoso será para um governo impor sua preferência quanto menor for a incerteza sobre o resultado gerado. Tendo acesso a maiorias superdimensionadas, governos preferirão inibir negociações e garantir decisões mais próximas do seu ponto ideal. Ao contrário, com alto grau de incerteza, é preferível optar pela negociação e reduzir as chances de obter-se resultado de soma zero em que o governo sai perdedor. Tais suposições teóricas estão baseadas nos resultados de pesquisas que mostram a relevância da obtenção de maiorias para o sucesso legislativo dos presidentes (BOND \& FLEISCHER, 1990; CAREY \& SHUGART, 1998; FIGUEIREDO \& LIMONGI, 1999; NICOLAU, 2000; INÁCIO, 2006; entre outros).

O argumento de Rikker (1962) também pode ajudar na fundamentação dessa hipótese. Se for possível explorar os argumentos relativos à coalizão minimamente vitoriosa também no contexto legislativo, então pode-se pensar que, embora esse raciocínio dependa de uma série de outros fatores, como, por

11 Como lembrado anteriormente, a dimensão eleitoral tem um peso considerável nesse processo. Decisões de tipo custos concentrados e benefícios dispersos (SARTORI, 1994) complicam esse quadro, já que mesmo assegurando maioria parlamentar, o governo precisa medir o efeito que a política terá na sociedade. Em alguns casos os efeitos podem ser desastrosos, comprometendo o objetivo central dos políticos: a manutenção de suas carreiras políticas. exemplo, do tipo de agenda do governo e das regras para a tomada de decisão, geralmente é o componente da incerteza que leva os chefes do Executivo a adotarem uma estratégia de segurança na composição de governos. Assim, as coalizões acabam sendo mais amplas do que necessário, já que existe a possibilidade de indisciplina por parte dos partidos aliados. De onde se pode deduzir, então, que coalizões minimamente vitoriosas têm um componente de incerteza considerável para o governo, o que amplia as chances de que resultados de soma positiva sejam observados.

Note-se que esse tipo de teorização leva em conta basicamente o número de participantes de uma coalizão. Uma teoria geral sobre o funcionamento dos governos necessita que se qualifique a observação de Rikker. A busca por resultados de soma positiva reduz as incertezas quanto às defecções e, de outro lado, aumenta as chances de que oposições legislativas contribuam no jogo da produção legislativa, durante a tramitação dos projetos. Sendo assim, os governadores não só buscarão a formação de coalizões minimamente vitoriosas no Legislativo, como o farão de modo a privilegiar a participação dos aliados e, também, dos oposicionistas, no processo de produção legislativa no interior do Legislativo. Os primeiros terão espaço propositivo, os segundos, terão respeitados seus direitos de veto.

Mais do que números, é preciso estar atento às posições. Se o critério numérico não é suficiente para a caracterização de uma coalizão, então, como já defendido, é preciso considerar o posicionamento ideológico dos atores em competição. Ou seja, para a formação de um governo não é apenas o número de cadeiras que tem de ser levado em conta, mas, sobretudo, o tipo de agenda compartilhada entre os potenciais aliados. Isso quer dizer que o grau de heterogeneidade ideológica das coalizões pode ter consequências sobre os resultados políticos de um governo.

É na confluência dessas três dimensões - o tamanho, a posição e a distribuição de poder - que este trabalho desenvolverá sua argumento. Nas próximas sessões, além de descrever os indicadores e dados utilizados para o teste das três hipóteses propostas, serão apresentadas variáveis de controle que, para efeito de teste de hipóteses, garantirão a possibilidade de se verificar as suposições feitas, à luz das possíveis hipóteses rivais às deste trabalho.

\section{V.DESENHO DA PESQUISA, DADOS E VARIÁVEIS}

\section{V.1. Taxa de Coalescência Estadual Ponderada}

O objetivo desta sessão é justificar a utilização do indicador ponderado de coalescência, originalmente 
desenvolvido por Amorim Neto (2000). Assim como o autor, parte-se de uma definição para a coalescência dos gabinetes: considera-se que quanto maior a proporcionalidade entre as cotas de secretarias dos partidos e seus pesos parlamentares, mais coalescentes são os gabinetes formados. A variável, assim medida, é contínua e será utilizada como fator explicativo dos resultados de soma positiva observados em cada um dos quatro governos analisados.

O indicador proposto é o seguinte:

Taxa de Coalescência ponderada ${ }^{12}$

$$
\text { Coal }_{p}=1-\frac{1}{2} \sum_{i=1}^{n}\left(\left|B_{i}-S_{i p}\right|\right)
$$

Sendo: $S_{i p}=\frac{o_{i}+c_{i}}{2}$

$\mathbf{B}_{\mathbf{i}}-$ proporção de cadeiras do partido $i$ dentro da coalizão de governo;

$\mathbf{S}_{\mathrm{ip}}$ - proporção de secretarias controladas pelo partido $i$ ponderado pelo orçamento de investimento e número de cargos comissionados de cada secretaria;

$\mathbf{O}_{\mathbf{i}}-$ proporção do orçamento de investimento da(s) secretaria(s) controlada(s) pelo partido $i$ considerando o orçamento de investimento das secretarias de estado (despesas de capital);

$\mathbf{C}_{i}$ - proporção de cargos comissionados na(s) secretaria(s) controlada(s) pelo partido $i$ considerando o total de cargos comissionados nas secretarias de estado.

Esse valor é calculado para cada gabinete montado. Os gabinetes são definidos com referência aos critérios adotados por Amorim Neto (2002). De maneira sagaz, Amorim Neto (2000) percebeu que os critérios propostos por Mueller e Strom (2000) para distinguir gabinetes não poderiam ser utilizados em sistemas presidencialistas, sobretudo porque as definições $1 \mathrm{e}$ 2 , mostradas acima, seriam mal aplicadas em arranjos definidos por mandatos fixos. Sendo assim, o autor apresenta a seguinte proposta: considera-se novo gabinete com (i) a posse de um novo presidente, (ii) uma mudança na composição partidária do gabinete $\mathrm{e}$ (iii) a mudança de mais da metade dos ministros. Como esses três critérios parecem suficientes para definir os gabinetes montados nos sistemas presidencialistas estaduais, optou-se por seguir as escolhas

12 A taxa de coalescência foi proposta por Amorim Neto (2000), a partir do Índice de Proporcionalidade de Rose (1984), que mede o montante de desvio da proporcionalidade entre votos e cadeiras de um partido em uma determinada eleição. metodológicas de Amorim Neto (2000; 2002) e aplicálas aos dois casos aqui estudados.

Para chegar à taxa de coalescência ponderada de um dado gabinete, primeiro realiza-se o somatório da proporção dos recursos de investimento disponíveis em cada secretaria e da proporção de cargos comissionados alocados por pasta, em cada mês de governo. O resultado é dividido por dois para que se tenha um indicador (Sip) que varie de 0 a 1 . Depois do cálculo do Sip, realiza-se o somatório do valor absoluto da diferença entre o percentual de orçamento de investimento e cargos comissionados por secretarias de cada partido e o percentual de cadeiras que cada partido controla do total de cadeiras controladas por todos os partidos que compõem o gabinete, quer eles detenham cadeiras nas assembleias ou não, e, no caso dos secretários de governo, quer pertençam a um partido ou não. Tal operação justifica-se porque matematicamente é possível identificar a relação de proporcionalidade entre cadeiras e recursos controlados pelos partido que fazem parte de cada gabinete.

O índice varia de zero (nenhuma correspondência entre volume de recursos políticos controlados nas secretarias e a porcentagem de cadeiras nas assembleias) a 1, número que define o limite superior de correspondência perfeita entre cotas no gabinete e peso legislativo dos partidos. A única exigência para essa operação é que pelo menos um ministro esteja ligado a um partido, o que não é problema para os casos analisados, conforme mostram os dados da seção anterior.

O detalhe é que a fórmula desenvolvida por Amorim Neto não considera o peso estratégico que cada pasta tem dentro do governo ${ }^{13}$. Como ele mesmo argumenta, "deve-se notar que [...] presume-se que todos os postos ministeriais são do mesmo valor. Porém, no mundo real da política, as coisas não são assim: alguns ministérios são mais importantes do que outros. [...] Entretanto, qualquer método que se use para quantificar os diversos valores políticos dos cargos ministeriais será sempre de baixa confiabilidade e passível a críticas. [...] Portanto, embora reconhecendo que o suposto de um mesmo valor político para todos os ministérios é uma solução imperfeita, sustento que é mais confiável do que qualquer tentativa de quantificar esse valor (AMORIM NETO, 2002, p. 54).

13 O autor chama atenção, ainda, para a suposição de que o poder de barganha de um partido é diretamente proporcional ao tamanho de sua bancada parlamentar. Com isso, ele desconsidera a relevância dos pivotal politics nos processos decisórios. Embora valha a pena ressaltar esse detalhe, não se encontrou nenhuma alternativa melhor para solucionar essa limitação. 
Diferentemente do que argumenta o autor, propõese ser possível, no caso dos gabinetes estaduais, utilizar o volume de recursos políticos e orçamentários, para distinguir o peso estratégico das secretarias. Primeiro, porque, nos estados, não há secretarias estaduais voltadas, exclusivamente, para funções administrativas relacionadas a missões internacionais que, mesmo com baixo recurso, tenderiam a ter peso relevante dentro do governo ${ }^{14}$. Segundo, porque, ao não se ponderar o peso de uma secretaria dentro de um gabinete estadual, a tendência é que o indicador apresente um viés de mensuração, relacionado à supervalorização de postos menos relevantes. Seria o caso de secretarias de Turismo e Comunicação, que têm menos relevância nos governos estaduais. Por fim, seria seriamente abalado o pressuposto de que partidos buscam votos, cargos e políticas para atender às demandas de suas bases eleitorais, caso não se considere que há pastas no governo mais interessantes estrategicamente exatamente porque controlam um alto volume de recursos, que poderão ser revertidos em capital eleitoral para seus controladores.

Os resultados desse cálculo ponderado mostram que tal opção metodológica faz variar consistentemente o indicador da taxa de coalescência, o que é interessante do ponto de vista da construção de modelos multivariados de explicação. Assim como faz Amorim Neto, apresenta-se, abaixo, a aplicação do indicador proposto em uma realidade hipotética.

QUADRO 1 - APLICAÇÃO TIPIFICADADATAXADE COALESCÊNCIA

\begin{tabular}{|lcc|c|c|c|c|c|}
\hline Partidos da Coalizão & Secretarias recebidas & $\mathbf{B}_{\mathbf{i}}$ & $\mathbf{O}_{\mathbf{i}}$ & $\mathbf{C}_{\mathbf{i}}$ & $\mathbf{S}_{\mathbf{i p}}$ & $\left|\mathbf{B}_{\mathbf{i}}-\mathbf{S}_{\mathbf{i p}}\right|$ \\
\hline $\mathrm{A}=20$ cadeiras & 2 & 0,31 & 0,70 & 0,6 & 0,65 & 0,34 \\
$\mathrm{~B}=35$ cadeiras & 0 & - & - & - & - & - \\
$\mathrm{C}=45$ cadeiras & 6 & 0,69 & 0,24 & 0,2 & 0,22 & 0,47 \\
& Técnico (1) & 0 & 0,055 & 0,1 & 0,078 & 0,078 \\
& Técnico (1) & 0 & 0,005 & 0,1 & 0,052 & 0,052 \\
Total $(\Sigma)$ & 10 & 1 & 1 & 1 & - & 0,94 \\
\hline
\end{tabular}

FONTE: O autor.

Imagine-se uma coalizão composta pelos partidos A e C. Eles controlam 65 cadeiras no Legislativo. O partido A controla $31 \%$ das cadeiras da coalizão e o partido C, 69\%. Há, também, técnicos indicados pelo governador que ocupam secretarias, mas não controlam nenhuma cadeira. O partido A ocupa a secretaria X e Y e elas possuem, respectivamente, um orçamento de investimento (capital e outros rendimentos) de 30000 e 40000 . O partido C controla as secretarias $\mathrm{Z}, \mathrm{W}, \mathrm{T}, \mathrm{H}, \mathrm{J}$ e $\mathrm{K}$, que possuem, respectivamente, um orçamento de 5 000, 500, 10000 , 5000,3000 e 500. A secretaria V, controlada pelo técnico 1, tem orçamento de 5500 e a secretaria Q do técnico 2, de 500. O orçamento de investimento total das secretarias de governo, no primeiro ano de mandato do governador em questão, foi de 100 000. Sendo assim, o partido A controla $70 \%$ do orçamento, o partido B, $24 \%$ e os técnicos 1 e $2,5,5 \%$ e $0,5 \%$, respectivamente. Dentro do total dos 100 cargos

14 Justificativa utilizada por Amorim Neto (2000) para não ponderar o peso dos ministérios. O exemplo utilizado é o do Ministério de Relações Exteriores, que tem baixo orçamento mas papel fundamental para o país. comissionados à disposição nas secretarias de estado, o partido A tem a sua disposição 60 , o partido C 20 , e os técnicos 1 e 2, 10 cada um. Essas distribuições podem ser vistas no Quadro 1. Com essas informações, basta aplicar as fórmulas 1 e 2 para se chegar ao valor da taxa de coalescência ponderada. Nesse exemplo, ela é de 0,53 .

A Tabela 5, a seguir, traz as informações sobre os gabinetes em MG e RG, entre 1999 e 2006, com a taxa de coalescência calculada para o período. Como se pode notar, a variação na taxa de coalescência dos gabinetes é grande. Os gabinetes variam de 0,05 (Aécio V) até 0,98 (Dutra II). Para que se tenha uma noção do que significa esse valor em termos comparativos, o gabinete presidencial brasileiro com valor mais alto de taxa de coalescência no período posterior à redemocratização é o de FHC I-2 $(0,70)$, enquanto que o menor é o Collor I $(0,40)$ (AMORIM NETO, 2007). A média da taxa de coalescência no período FHC é de 0,585 e no período Lula é de 0,550. Observe-se que a variação encontrada nos dois estados aqui analisados é maior do que a calculada para o plano nacional.

Outro detalhe interessante é que os gabinetes mineiros duram, em média, muito menos (262 dias) 
TABELA5 - GABINETES ESTADUAIS, COMPOSIÇÃO, BANCADALEGISLATIVA, TAXADE COALESCÊNCIAE DURAÇÃO - RIO GRANDE DO SUL E MINAS GERAIS (1999-2006).

\begin{tabular}{|c|c|c|c|c|c|}
\hline Período & Gabinete & Partidos & $\begin{array}{l}\text { Coalescência } \\
\text { tradicional }\end{array}$ & $\begin{array}{c}\text { Coalescência } \\
\text { ponderada }\end{array}$ & $\begin{array}{c}\text { Duração } \\
\text { (dias) }\end{array}$ \\
\hline jan.99 nov.99 & Dutra I & PT - PSB - PDT & 0,82 & 0,79 & 334 \\
\hline dez.99 dez.00 & Dutra II & PT - PSB & 0,97 & 0,98 & 396 \\
\hline jan.01 dez.02 & Dutra III & PT - PSB - PCdoB & 0,84 & 0,89 & 730 \\
\hline jan.03 dez.03 & Rigotto I & PMDB - PSDB - PDT - PP - PTB & 0,72 & 0,64 & 365 \\
\hline jan.04 fev.05 & Rigotto II & PMDB - PSDB - PDT - PP - PTB & 0,77 & 0,77 & 424 \\
\hline mar.05 fev.06 & Rigotto III & PMDB - PSDB - PDT - PP - PTB & 0,76 & 0,80 & 365 \\
\hline mar.06 dez.06 & Rigotto IV & PMDB - PTB & 0,61 & 0,44 & 306 \\
\hline jan.99 fev.99 & Itamar I & PMDB - PFL - PDT - PT - PSB & 0,64 & 0,49 & 59 \\
\hline mar.99 mar.99 & Itamar II & PMDB - PFL - PDT - PT - PSB & 0,58 & 0,46 & 31 \\
\hline abr.99 jun.99 & Itamar III & PMDB - PFL - PDT - PT - PSB & 0,63 & 0,49 & 91 \\
\hline jul.99 out.99 & Itamar IV & PMDB - PFL - PDT - PT - PSB & 0,58 & 0,47 & 123 \\
\hline nov.99 dez.99 & Itamar V & PMDB - PFL - PDT - PT - PSB & 0,67 & 0,51 & 61 \\
\hline jan.00 jan.00 & Itamar VI & PMDB - PFL - PDT - PT - PSB & 0,71 & 0,55 & 31 \\
\hline fev.00 fev.00 & Itamar VII & PMDB - PFL - PDT - PT - PSB & 0,66 & 0,54 & 28 \\
\hline mar.00 mar.00 & Itamar VIII & PMDB - PFL - PDT - PT - PSB & 0,71 & 0,45 & 31 \\
\hline abr.00 abr.00 & Itamar IX & PMDB - PFL - PDT - PT - PSB & 0,75 & 0,57 & 30 \\
\hline mai.00 mai.00 & Itamar X & PMDB - PFL - PDT - PT & 0,70 & 0,56 & 31 \\
\hline jun.00 jun.00 & Itamar XI & PMDB - PFL - PDT & 0,60 & 0,57 & 30 \\
\hline jul.00 fev.01 & Itamar XII & PMDB - PFL - PDT & 0,55 & 0,55 & 243 \\
\hline mar.01 mar.01 & Itamar XIII & PMDB - PFL - PDT & 0,50 & 0,55 & 31 \\
\hline abr.01 abr.01 & Itamar XIV & PMDB - PFL - PDT & 0,45 & 0,28 & 30 \\
\hline mai.01 jun.01 & Itamar XV & PMDB - PFL - PDT & 0,40 & 0,25 & 61 \\
\hline jul.01 nov.01 & Itamar XVI & PMDB - PFL - PDT & 0,43 & 0,28 & 153 \\
\hline dez.01 mar.02 & Itamar XVII & PMDB - PFL - PDT & 0,35 & 0,20 & 121 \\
\hline abr.02 dez.02 & Itamar XVIII & PMDB - PFL & 0,28 & 0,14 & 275 \\
\hline jan.03 jan.04 & Aécio I & PSDB - PP - PL - PSB - PTB - PDT & 0,52 & 0,22 & 396 \\
\hline fev.04 mai.04 & Aécio II & PSDB - PP - PL - PSB - PTB - PDT & 0,53 & 0,23 & 120 \\
\hline jun.04 jun.04 & Aécio III & PSDB - PP - PL - PTB - PDT & 0,47 & 0,22 & 30 \\
\hline jul.04 jul.04 & Aécio IV & PSDB - PP - PL - PTB - PMDB - PPS & 0,47 & 0,38 & 31 \\
\hline ago.04 jan.05 & Aécio V & PSDB - PP - PL - PTB - PMDB - PPS - PFL & $\mathrm{FL} \quad 0,53$ & 0,05 & 184 \\
\hline fev.05 fev.06 & Aécio VI & $\begin{array}{c}\text { PSDB - PP - PL - PTB - PMDB } \\
\text { - PPS - PFL - PDT }\end{array}$ & 0,59 & 0,36 & 393 \\
\hline mar.06 dez.06 & Aécio VII & PSDB - PP - PMDB - PPS - PDT & 0,36 & 0,20 & 306 \\
\hline
\end{tabular}

FONTE: O autor, a partir do banco de dados de produção legislativa (MG e RS) (NUNES, 2009b).

do que os gabinetes gaúchos (450 dias). O gabinete presidencial brasileiro que durou mais tempo no período posterior à redemocratização foi o de FHC I-2 (990 dias), enquanto que o de menor duração foi o Lula I-4 (60 dias) (AMORIM NETO, 2007). Importa, ainda, enfatizar a especificidade do governo Itamar Franco (PMDB) quanto ao número de gabinetes montados: no seu período à frente ao governo de $\mathrm{MG}, 18$ foram as mudanças na composição do seu gabinete. 


\section{V.2. Contiguidade Ideológica e Contingente Legis- lativo}

As outras duas variáveis independentes importantes já foram mostradas na seção anterior. Observa-se claramente a tendência de que as coalizões, nos dois estados, sejam heterogêneas e não-contíguas. Mas vale destacar três aspectos:

(I) Nem todos os governos estaduais logram, pelos acordos partidários envolvendo a distribuição de postos políticos no primeiro escalão, conquistar maiorias legislativas no interior do Legislativo. O governo Dutra no RS não consegue ou não se dispõe a conquistar maioria no Legislativo, por meio da composição de uma coalizão partidária no âmbito das secretarias de estado. Em Minas, Itamar Franco também não obtém uma coalizão majoritária, embora, se comparado a Dutra, tenha conseguido reunir um contingente legislativo maior do que o seu colega gaúcho. Rigotto e Aécio, ao contrário, na maior parte de seus mandatos, contam com folgadas maiorias no Legislativo.
Essas constatações permitem propor duas hipóteses: a primeira, que a utilização de cooptação como estratégia para se alcançar apoio legislativo ainda está presente na relação entre os poderes; e a segunda, que os Governadores estão dispostos a negociar as matérias com partidos independentes e de oposição, durante sua tramitação no Legislativo. Para verificar se essas hipóteses se sustentam, seria necessário fazer um teste em que se comparasse o comportamento dos partidos políticos, em votações nominais que envolvessem decisões importantes para o governo. Caso uma maioria de parlamentares se comporte de forma a apoiar os projetos do governo, mesmo sem haver pactos políticos envolvendo cargos na burocracia do estado, poder-se-ia afirmar a operação de uma coalizão de governo, talvez, em bases programáticas. Outro teste interessante seria observar os pronunciamentos dos parlamentares e averiguar se criticam ou elogiam as propostas de autoria do Executivo, em tramitação na Casa. Tais exercícios, no entanto, não serão realizados aqui.

TABELA 6 - GABINETES ESTADUAIS, DURAÇÃO, CONTIGUIDADE, NÚMERO DE ALIADOS E HOMOGENEIDADE IDEOLÓGICA - RIO GRANDE DO SUL E MINAS GERAIS (1999-2006)

\begin{tabular}{|c|c|c|c|c|}
\hline Gabinete & Bancada & Contígua & Homogênea & Parceiros \\
\hline Dutra I & 36,4 & Sim & Sim & 3 \\
\hline Dutra II & 21,8 & Sim & Sim & 2 \\
\hline Dutra III & 21,8 & Sim & Sim & 3 \\
\hline Rigotto I & 63,6 & Não & Não & 5 \\
\hline Rigotto II & 63,6 & Não & Não & 5 \\
\hline Rigotto III & 65,5 & Não & Não & 5 \\
\hline Rigotto IV & 29,6 & Sim & Não & 2 \\
\hline Itamar I & 44,2 & Não & Não & 5 \\
\hline Itamar II & 44,2 & Não & Não & 5 \\
\hline Itamar III & 44,2 & Não & Não & 5 \\
\hline Itamar IV & 44,2 & Não & Não & 5 \\
\hline Itamar V & 44,2 & Não & Não & 5 \\
\hline Itamar VI & 46,8 & Não & Não & 5 \\
\hline Itamar VII & 46,8 & Não & Não & 5 \\
\hline Itamar VIII & 46,8 & Não & Não & 5 \\
\hline Itamar IX & 46,8 & Não & Não & 5 \\
\hline Itamar X & 44,2 & Não & Não & 4 \\
\hline Itamar XI & 36,4 & Não & Não & 3 \\
\hline Itamar XII & 36,4 & Não & Não & 3 \\
\hline Itamar XIII & 35,1 & Não & Não & 3 \\
\hline Itamar XIV & 35,1 & Não & Não & 3 \\
\hline Itamar XV & 35,1 & Não & Não & 3 \\
\hline Itamar XVI & 35,1 & Não & Não & 3 \\
\hline Itamar XVII & 32,5 & Não & Não & 3 \\
\hline Itamar XVIII & 22,1 & Não & Não & 2 \\
\hline Aécio I & 59,8 & Não & Não & 6 \\
\hline Aécio II & 53,3 & Não & Não & 6 \\
\hline Aécio III & 50,7 & Não & Não & 5 \\
\hline Aécio IV & 59,8 & Sim & Não & 6 \\
\hline Aécio V & 66,3 & Sim & Não & 7 \\
\hline Aécio VI & 72,7 & Não & Não & 8 \\
\hline
\end{tabular}

FONTE: O autor, a partir do banco de dados de produção legislativa (MG e RS) (NUNES, 2009b). 
(II) Como já observado anteriormente, há uma tendência clara de que os gabinetes sejam nãocontíguos. De todo o período analisado, apenas o governo Dutra possui consistência na produção de coalizões com partidos contíguos ideologicamente. No governo Itamar não há nenhum gabinete contíguo e nos governo Rigotto e Aécio, apenas em um período curto de tempo. Embora pequena, será preciso testar se essa variação auxilia na explicação dos resultados de soma positiva.

Para a construção dessa variável indicadora, foi utilizada uma distribuição espacial em que foram posicionados todos os partidos com participação nas assembleias legislativas em uma escala de esquerda e direita $^{15}$. Foi considerado contíguo o gabinete que continha partidos políticos alinhados sequencialmente. Embora seja um critério essencial para esta análise, é preciso reconhecer que se trata de mensuração muito exigente. Na maioria dos casos, embora não se observe contiguidade, é possível identificar proximidade ideológica. Por exemplo, o gabinete Aécio I, só não contém o PMDB e o PFL para que o gabinete torne-se contíguo. Mesmo reconhecendo tal limitação, optou-se por manter a estratégia metodológica proposta para tentar captar, de forma mais precisa, o efeito da contigüidade sobre a obtenção dos resultados de soma positiva.

(III) Por fim, importa lembrar, mais uma vez, que o arranjo institucional subnacional, sobretudo o sistema eleitoral dos estados, a exemplo do que se observa no plano nacional, tende a gerar um sistema partidário tão fragmentado que inviabiliza, primeiramente, que maiorias legislativas sejam cimentadas eleitoralmente e, depois, que um governo de coalizão majoritário forme-se dentro de um único campo ideológico. Os dados são claros: todas as coalizões majoritárias são heterogêneas ideologicamente e todas as coalizões homogêneas são minoritárias no Legislativo. Esse paradoxo entre tamanho e ideologia gera contextos interessantes do ponto de vista teórico, já que, necessariamente, a negociação por políticas e por cargos deve levar em conta a interação entre essas duas dimensões. O que é mais efetivo, formar governos homogêneos, programáticos e minoritários ou heterogêneos, com bases na patronagem, mas majoritários?

\footnotetext{
15 Para a construção dessa escala foram considerados os resultados de estudos sobre posicionamento ideológico de partidos político no Brasil nos níveis nacional e subnacional. A escala final ficou ordenada da seguinte forma: PSOL, PCdoB, PT, PSB e PDT, PPS, PSDB, PMDB, PR (PL), PTB, DEM, PP. Sobre esse tema ver Saiegh (2004), Melo e Nunes (2008), Castro, Anastasia e Nunes (2009) e Power e Zucco (2009).
}

Se a pergunta é levada aos interessados na governabilidade por meio de resultados de soma zero, aqueles interessados nas votações nominais, na disciplina e na coesão partidária, a segunda opção provavelmente prevalece. Mas se o interesse é nas decisões em que todos podem ganhar, em que mais de um angaria resultados, e que o governo, não obtendo maioria, consegue negociar com os partidos presentes no Legislativo o conteúdo das matérias, talvez a resposta seja outra.

\section{V.3. Decurso de Mandato e Ativos Institucionais}

Além da taxa de coalescência, do contingente legislativo e da contiguidade das coalizões, dois outros fatores serão utilizados como variáveis de controle: o decurso do mandato e o controle de ativos institucionais.

A respeito do decurso do mandato, há consenso na literatura especializada sobre o efeito que os ciclos eleitorais têm sobre a obtenção de resultados legislativos, em sistemas presidencialistas. Haveria, segundo os autores, dois momentos claramente distintos: o início do mandato, caracterizado como uma "lua de mel" entre Legislativo e Executivo, e o final do mandato, em que os atores em competição percebem a necessidade de configurar novas alianças, com vistas às eleições que se aproximam (SHUGART \& CAREY, 1992; MAINWARING, 1993; CAREY, 2000; AMORIM NETO, 2002).

A instituição da reeleição para os cargos executivos, principalmente na América Latina, complexificou esse cenário (ALEMAN \& CALVO, 2007), já que presidentes e governadores, com a possibilidade de serem reeleitos, podem ter maiores ou menores chances reais de serem reconduzidos. Os partidos, além de atentar para os custos e benefícios de se manterem no governo ou na oposição, têm de identificar quais são as chances reais de cada grupo na competição. No Brasil, essa questão passa a existir desde 1998, com a aprovação da PEC da reeleição, no governo FHC, em 1997. Após essa data, todos os cargos executivos podem ser ocupados por dois mandatos consecutivos, pelo mesmo político. No período aqui analisado, embora tal prerrogativa já estivesse em vigor, nenhum governador foi reeleito: nem Itamar Franco nem Olívio Dutra conseguiram a reeleição nos seus estados, embora tenham tentado.

A utilização do decurso do mandato como variável de controle replica o estudo de Amorim Neto (2002) para o Brasil. Seus resultados mostram que quanto mais se aproxima o fim do mandato, menor é a disciplina partidária no Legislativo, embora haja variação do efeito encontrado sobre o grau de apoio aos projetos do presidente, por partido político. 
Por fim, utilizar-se-á como variável de controle o acesso que os partidos aliados têm sobre ativos institucionais (INÁCIO, 2006). Para a autora, o domínio desse tipo de recurso facilita que matérias indesejadas pelo governo não passem das instâncias de controle do Legislativo. Seus resultados mostram, para o período posterior à redemocratização, que o fato de o Presidente da Câmara ser membro da coalizão representa um aumento considerável no índice de apoio ao governo, mesmo controlando a taxa de disciplina e a contiguidade ideológica.

$\mathrm{O}$ argumento é desenvolvido à luz das teorias de cartel desenvolvidas por Cox e McCubbins (1993; 2005). Segundo os autores, o sucesso legislativo de um presidente será maior quanto mais amplo for o seu controle sobre os postos-chave na estrutura do Legislativo. Conquistando os cargos da mesa diretora e das comissões estratégicas (Comissão de Constituição e Justiça e Comissão de Fiscalização Financeira e Orçamentária), o governo será capaz de vetar ou neutralizar o acesso de legislação que possa vir a dividir a base governista. Portanto, os poderes de agenda do chefe do Executivo não seriam suficientes para garantir sucesso legislativo ao seu governo, embora seja necessário considerar a relevância de sua capacidade de veto.

Amorim Neto, Cox e McCubbins (2003) utilizam a mesma lógica de análise aplicando-a ao caso brasileiro. Eles mostram que nem todos os presidentes foram capazes de compor coalizões governativas majoritárias, embora os resultados expressem alto sucesso legislativo. Os autores sugerem, assim, que o uso de poderes unilaterais à disposição dos governos seria responsável pela manutenção do sucesso, mesmo sem apoio majoritário no Legislativo ${ }^{16}$.

Neste trabalho, a utilização dessa dimensão teórica permitirá isolar o efeito que o acesso a postos de comando na estrutura legislativa tem sobre a capacidade do governo de gerar resultados de soma zero e positiva. Na direção do que a literatura tem produzido, espera-se que o controle sobre os postos legislativos funcione como um facilitador para a obtenção de resultados de soma positiva, já que os temas que dividem o plenário são bloqueados antes mesmo de serem inseridos no parlamento.

\section{RESULTADOS}

Para testar as hipóteses 1, 2 e 3, utilizou-se uma base de dados que tem como unidade de análise todos os Projetos de Lei, Projetos de Emenda Constitucional e Projetos de Lei Complementar apresentados pelo Executivo em Minas Gerais e no Rio Grande do Sul,

16 Para um debate mais profícuo sobre esse tema ver Figueiredo (2006). entre 1999 e 2006. Para alimentar essa base de dados foi preciso trabalhar, primeiro, na sistematização das informações sobre as secretarias estaduais e as votações nominais nesses dois estados, para o período analisado ${ }^{17}$. Com os dados organizados, passou-se à utilização de um modelo de regressão logística binária para a variável dummy: resultados de soma zero $(=0)$ e resultados de soma positiva $(=1)$. A equação final estimada está graficamente apresentada abaixo:

$$
\operatorname{Ln}\left(\frac{P(\text { result }=1)}{1-P(\text { result }=1)}\right)=\beta_{o}+\beta_{i} X_{i}+\varepsilon
$$

Onde $X_{i}$ e um vetor de varı́vers independentes:

"Resultado" = variável dummy que indica (1) se a matéria foi decidida por procedimentos que levam a resultados de soma positiva e (0) se dão origem a resultados de soma zero;

"Coalescência" = taxa de coalescência ponderada calculada para cada um dos gabinetes estaduais entre 1999 e 2006;

"Contiguidade" = variável dummy que indica (1) se a coalizão montada é contigua e (0) se não;

"Coalizão" = percentual de cadeiras que os partidos que compõem o gabinete ocupam na Assembleia;

"Decurso" = número de dias que restam até o último dia do mandato do governador do estado;

"Ativos" = variável dummy que indica (1) se o Presidente da Assembleia é filiado a um partido que faz parte da coalizão formal de governo e (0) se não;

"Votos Sim" = percentual de votos favoráveis que o projeto recebeu em plenário;

"Centralização" = variável categórica que indica o grau de centralização de poder nas mãos do Presidente da Assembleia Legislativa;

"Governo" = percentual de cadeiras controladas pelo partido do Governador.

A vantagem da utilização de modelos logit, segundo Garson (2009), é que ele não requer que as variáveis estejam distribuídas normalmente, não assume pressupostos de homoscedasticidade, nem de multicolina-

\footnotetext{
17 É preciso agradecer os assistentes de pesquisa Rafael Scherer, aluno de Ciências sociais da UFRGS, e Mariana Canaan, aluna de ciências sociais da UFMG que me ajudaram na coleta dos dados para a composição da taxa de coalescência. Além deles, agradeço às consultorias técnicas das Assembléias Legislativas de Minas Gerais e do Rio Grande do Sul, bem como ao corpo técnico da PROSERGS, do PRODEMG, da Biblioteca Pública dos dois estados, dos Tribunais de Contas dos dois estados e do Arquivo Público dos dois estados. Sem a colaboração dos funcionários desses órgãos seria impossível ter acesso às informações utilizadas neste trabalho.
} 
riedade. Isso é relevante para este trabalho porque, ao observar os resultados dos testes para identificar se havia algum tipo de associação entre as variáveis independentes, notou-se alta correlação entre contiguidade e contingente legislativo $(-0,742)$, entre contiguidade e ativos institucionais $(-0,708)$ e entre contingente legislativo e ativos institucionais $(0,713)$.

Conforme a leitura da Tabela 7 esclarece, os modelos elaborados parecem razoáveis, já que explicam entre $3 \%$ e $52 \%$ da variância da variável dependente. Além disso, o modelo multivariado melhor ajustado é o número 5 , já que apresenta o menor valor do teste do qui-quadrado dentre as regressões multivariadas propostas. Esses diferentes modelos foram propostos para se compreender melhor a relação entre as variáveis independentes e intervenientes e a variável dependente. A mobilização de diferentes variáveis em modelos multivariados é importante, porque permite identificar efeitos relevantes e significativos, sob o efeito de controles teoricamente relevantes.

TABELA 7 - REGRESSÃO LOGÍSTICA BINÁRIA. VAR. DEPENDENTE: TIPO DE RESULTADO LEGISLATIVO (SOMA POSITIVA = 1)

\begin{tabular}{|c|c|c|c|c|c|}
\hline & Mod 1 & Mod 2 & Mod 3 & Mod 4 & Mod 5 \\
\hline (Intercepto) & $\begin{array}{c}2.62^{* * *} \\
(0.14)\end{array}$ & $\begin{array}{c}15.8 \\
(831.4)\end{array}$ & $\begin{array}{l}220.32 \\
(125.1)\end{array}$ & $\begin{array}{l}-11.67 \\
(844.2)\end{array}$ & $\begin{array}{c}5.98 \\
(853.7)\end{array}$ \\
\hline Estado: MG/RS & $\begin{array}{l}1.12^{* *} \\
(0.35)\end{array}$ & $\begin{array}{c}1.17^{* * *} \\
(0.35)\end{array}$ & $\begin{array}{l}1.13^{* *} \\
(0.35)\end{array}$ & & \\
\hline Tipo: PL/PEC & & $\begin{array}{l}-13.08 \\
(831.4)\end{array}$ & & & \\
\hline Tipo: PLC/PEC & & $\begin{array}{l}-14.50 \\
(831.4)\end{array}$ & & & \\
\hline Ano & & & $\begin{array}{l}-0.11 \\
(0.06)\end{array}$ & & \\
\hline Contiguidade & & & & $\begin{array}{l}7.54^{* *} \\
(2.52)\end{array}$ & $\begin{array}{l}-1.99 \\
(3.80)\end{array}$ \\
\hline Coalizão & & & & $\begin{array}{l}0.18^{\star *} \\
(0.07)\end{array}$ & $\begin{array}{l}-0.01 \\
(0.09)\end{array}$ \\
\hline Ativos: Sim/Não & & & & $\begin{array}{l}-11.07 \\
(844.2)\end{array}$ & $\begin{array}{l}-11.69 \\
(853.6)\end{array}$ \\
\hline Votos Sim & & & & $\begin{array}{c}0.19^{\star * *} \\
(0.03)\end{array}$ & $\begin{array}{c}0.20^{* * *} \\
(0.03)\end{array}$ \\
\hline Decurso (dias) & & & & $\begin{array}{c}0.00 \\
(0.00)\end{array}$ & $\begin{array}{c}0.00 \\
(0.00)\end{array}$ \\
\hline Centralização & & & & $\begin{array}{l}1.74^{*} \\
(0.68)\end{array}$ & $\begin{array}{l}-1.29 \\
(1.18)\end{array}$ \\
\hline Coalescência & & & & & $\begin{array}{c}-10.11^{*} \\
(4.16)\end{array}$ \\
\hline Governo & & & & & $\begin{array}{l}0.68^{*} \\
(0.29)\end{array}$ \\
\hline McFadden R-sq. & 0.03 & 0.05 & 0.03 & 0.46 & 0.47 \\
\hline Nagelkerke R-sq. & 0.03 & 0.06 & 0.04 & 0.51 & 0.52 \\
\hline Likelihood-ratio & 12.79 & 23.39 & 15.96 & 232.17 & 240.88 \\
\hline Deviance & 497.03 & 486.44 & 493.872 & 277.66 & 268.95 \\
\hline $\mathrm{AIC}$ & 501.03 & 494.44 & 499.872 & 291.66 & 286.95 \\
\hline $\mathrm{N}$ & 1240 & 1240 & 1240 & 1240 & 1240 \\
\hline
\end{tabular}

FONTE: O autor, a partir do banco de dados de produção legislativa (MG e RS) (NUNES, 2009b).

NOTA: (1) A tabela mostra os valores beta estimados e os erros padrões entre parênteses. Para identificar a magnitude do efeito de cada variável independente é preciso calcular o exponencial dos betas estimados, diminuir de 1 e multiplicar por 100. Assim, é possível tratar da probabilidade de que o evento ocorra pelo controle das variáveis do modelo. $\mathrm{P}<0.050{ }^{*} \mathrm{P}<0.001$. 
Embora nem todas as variáveis explicativas tenham dado significância estatística, a direção e a magnitude dos efeitos esperados nas hipóteses 1, 2 e 3 são observadas nos resultados encontrados no modelo 5 .

A principal hipótese deste trabalho é corroborada em todos os modelos propostos. Além de significativo, o efeito que a coalescência tem sobre a probabilidade de obter-se resultados de soma positiva é robusto e negativo. Isto é, mesmo com os controles incluídos, o aumento de um ponto na taxa de coalescência eleva, em média, em $-99 \%$ a probabilidade de que um resultado de soma positiva seja observado, se comparado com um resultado de soma zero. O valor é expressivo e indica o esperado teoricamente.

No caso da contiguidade, o resultado não é robusto o suficiente para que alguma conclusão possa ser tirada. No modelo que conta com a variável "ativos institucionais", seu efeito perde significância estatística. Embora a interpretação de efeitos de betas não significativos seja controversa na estatística, vale a pena chamar a atenção para o fato de que, mesmo sob os controles impostos, coalizões contíguas têm, em média, $-86 \%$ de chance de chegar a resultados de soma positiva do que se chegar a resultados de soma zero. $\mathrm{O}$ efeito do contingente legislativo dá-se na direção esperada. No entanto, o tamanho do coeficiente é pequeno e o beta também perde significância estatística com a introdução dos ativos institucionais, como variável de controle. O resultado aponta que, mesmo com os controles, um ponto percentual a mais no contingente legislativo da coalizão reduz, em média, em $1 \%$ as chances de que se observe um resultado de soma positiva em relação a um resultado de soma zero.

Da análise dos resultados referentes a essas três variáveis parece claro que a taxa de coalescência tem relevância explicativa, mesmo sob o controle das variáveis explicativas utilizadas pela literatura. No caso da contiguidade e do contingente da coalizão, seus efeitos parecem ser determinados pelo controle que o governo faz dos recursos institucionais à disposição no Legislativo.

Mas há outros dois resultados que chamam a atenção. Primeiro, a variável "estado" perde efeito estatisticamente significativo quando contrastada com as três variáveis explicativas mais importantes deste trabalho. Ou seja, é possível observar a conexão causal hipotetizada anteriormente, independentemente do estado que se esteja analisando. Ademais, a direção do coeficiente mostra que o estado de $\mathrm{MG}$, em comparação com o RS, tem, em média, mais projetos que são resultados de decisões de soma positiva.

Segundo, embora o aumento no número de cadeiras controladas por uma coalizão no Legislativo tenda a gerar um menor número de resultados de soma positiva, o aumento no número de cadeiras controladas pelo partido do governador gera efeito significativo e expressivo sobre a probabilidade de observarem-se resultados de soma positiva. Nos três modelos em que é utilizada, a variável apresenta significância e seu efeito é reduzido apenas quando a variável "ativos institucionais" é incluída no modelo. Isso sugere, portanto, a necessidade de pesquisas para explicar qual a relação entre o papel do partido do governador nas coalizões governativas e os resultados legislativos observados.

\section{CONCLUSÕES}

Este trabalho analisou a produção de decisões nos estados de MG e RS sob a óptica da obtenção de resultados de soma positiva em governos de coalizão. Interesse especial recaiu sobre a identificação das conexões causais entre os atributos dos governos de coalizão observados e o tipo de resultado legislativo auferido. O objetivo geral do estudo foi contribuir para a compreensão dos processos decisórios no âmbito dos estados no período posterior a 1994 e ampliar a abrangência dos estudos sobre os poderes estaduais no Brasil. Discutiram-se os fatores que incentivam os deputados estaduais, reunidos em bancadas partidárias, juntamente com o Executivo, a conduzir a agenda política em pauta.

A motivação do estudo surgiu com a inquietação acerca da afirmação de que a relação entre os poderes estaduais é marcada por um "pacto homologatório". Reconhecendo que a pesquisa de Abrucio fazia referência a um momento específico no tempo, não parecia razoável utilizar as referidas conclusões para se tentar entender o atual contexto político estadual brasileiro. Afinal, parece consenso que o Legislativo fortaleceu-se e o Executivo debilitou-se após o período estudado por ele. Refere-se aqui às consequências das reformas empreendidas pelo Presidente Fernando Henrique Cardoso e à estabilização econômica e política desse período.

Os casos de Minas Gerais e Rio Grande do Sul foram escolhidos por representar, segundo pesquisas anteriores, os estados brasileiros que mais avançaram no fortalecimento de suas estruturas legislativas. Acreditava-se que, se fosse possível mostrar que nesses dois estados o padrão decisório havia tomado uma forma mais estruturada, seria razoável argumentar a existência de um padrão variado - no tempo e no espaço - entre os estados no que se refere a esse quesito. Ou melhor, que os estados que se desenvolveram institucionalmente e que conseguiram estruturar seus subsistemas partidários seriam capazes de passar de um modelo de cooptação - marca do 
ultrapresidencialismo - para um modelo de coalizão partidária.

Com essa provocação teórica e a oportunidade de fazer pesquisa empírica nesses dois estados, a primeira suspeita era a de que a interpretação acerca do ultrapresidencialismo era mantida por causa da forma como os resultados legislativos vinham sendo apreendidos pela literatura especializada. Como mostrado no início do artigo, medir o sucesso legislativo de um governo pela taxa de aprovação das matérias que ele apresenta tende a mascarar a importância que o Legislativo tem no processo de tomada de decisão. Os acordos e as negociações que tinham lugar no interior do Legislativo eram tomados como dados e não eram vistos como relevantes para o entendimento da política estadual. A aprovação massiva dos projetos de autoria do governador parecia ser evidência suficiente de que ele continuava a "ditar as regras" no estado. Uma primeira alternativa, no entanto, pareceu ser a proposição de uma nova medida de sucesso baseada na forma como as decisões eram tomadas no Legislativo.

Utilizando as ferramentas analíticas propostas por Sartori (1994), este trabalho classificou as matérias legislativas de autoria do Governador entre resultados de soma positiva e resultados de soma zero. Isso só foi possível porque as assembleias foram tomadas como sistemas de comitês: organizações institucionalizadas, que tem um código operacional próprio, que decidem por fluxo contínuo e interação face a face nas suas instâncias decisórias. Um dos traços característicos dos comitês é a forma de decisão. Em geral, as decisões obtidas beneficiam todos os participantes. Se não podem legislar, pelo menos, está garantida, inclusive à minoria, a possibilidade de vetar questões que não são do seu interesse.

Com essa estrutura interpretativa, as decisões que chegaram ao seu último passo no processo de tramitação com o acordo dos atores em competição no Legislativo foram classificadas como resultados de soma positiva. E as decisões que chegaram ao plenário ainda em impasse foram tomadas como resultados de soma zero. A justificativa para essa classificação foi tentar identificar o volume de proposições que ao tramitar no Legislativo geraram condições para que todos pudessem ganhar, em contraposição às matérias em que a vitória de um geraria, necessariamente, a derrota do outro.

Infelizmente, vale destacar, não foi possível avançar ainda mais na composição desse novo indicador. Reconhece-se como fundamental para a ampliação do escopo do trabalho a inclusão da dimensão "emendamento" como indicador da participação do
Legislativo na construção de matérias legais no âmbito dos estados. Se for possível mostrar que, nos legislativos desenvolvidos institucionalmente e estruturados partidariamente, a matéria aprovada ou rejeitada no final da tramitação tem a participação determinante dos deputados, seria plausível o argumento de que estados com esse perfil tenderiam a produzir legislação que geraria ganhos para o conjunto dos competidores. Acredita-se que essa incorporação pode ser tomada como um dos mais importantes desdobramentos deste trabalho.

Ressalva à parte, os resultados mostraram que, em geral, a grande parte das matérias era decidida por meio de procedimentos que geravam resultados de soma positiva. Exatamente na direção e com a magnitude esperada inicialmente. Mas os resultados de soma positiva, mesmo sendo maioria, variavam entre os governos estudados. Nos governos Aécio e Dutra, os resultados de soma positiva foram a regra em todo o mandato. Diferentemente, Rigotto e Itamar acumularam cerca de $10 \%$ de proposições que geraram resultados de soma zero. Diante dessa observação, o desafio passou a ser o de identificar o papel dos partidos na montagem das coalizões e, posteriormente, explicar porque, nesses dois estados, tal variação é observada.

Para tanto, a discussão deste trabalho passou a focar na forma como os governos foram montados. Ainda preocupado com a generalização a respeito do ultrapresidencialismo, o trabalho buscou responder se era possível, nos moldes encontrados no nível nacional, definir o tipo de governo encontrado nos estados como sendo uma coalizão. O desafio era saber se a cooptação de deputados para a formação de coalizões ad hoc prevalecia sobre a estratégia de composição de coalizões partidárias utilizando os recursos à disposição do governador.

Nos dois casos, os partidos têm presença contundente nas coalizões. Seja no que diz respeito ao número, seja no que se refere à distribuição das preferências dos mesmos, observa-se que eles foram acionados como elementos que agregam força política para o governo do estado. Mas há variações interessantes que mereceram ser reportadas. No RS as coalizões duram, em média, mais do que em MG. No que se refere à contiguidade das mesmas, apenas o governo Dutra atendeu a esse quesito durante todo o mandato. O governo Itamar, ao contrário, não apresenta contiguidade em nenhuma de suas coalizões. Detalhe interessante é que apenas os governos Rigotto e Aécio compõem maioria legislativa por meio da coalizão partidária montada. Se esse resultado fosse analisado de maneira isolada, ele poderia indicar que os governadores utilizam predominantemente a cooptação 
de deputados para aprovar sua agenda. O que se está chamando atenção, no entanto, é que resultados de soma positiva, que podem ser mais interessantes eleitoralmente para o governo, podem ser conquistados mesmo sem o apoio formal desse maior número de deputados no legislativo.

Na sua última parte, o trabalho passou a dedicar-se ao entendimento das conexões causais entre os atributos das coalizões montadas e o volume de resultados de soma positiva alcançados pelos governos. As principais variáveis mobilizadas para tentar explicar a variação dos resultados de soma positiva em cada governo foram: (i) taxa de coalescência, (ii) decurso do mandato, (iii) contingente legislativo do partido do governador e da coalizão de governo, (iv) controle de ativos institucionais e $(v)$ contiguidade ideológica da coalizão.

Todas as variáveis utilizadas seguem a mensuração proposta em outros estudos comparados ou transversais. Exceto o indicador de taxa de coalescência. Desenvolvido por Amorim Neto, a medida é muito útil para mostrar como se dá a relação política entre o chefe do Executivo e os partidos com representação parlamentar. No entanto, acredita-se, seria possível incrementar a utilidade e a eficácia da medida se houvesse uma forma de ponderar a força das secretarias, se não completamente, pelo menos, no que diz respeito ao volume de recursos disponíveis. Os gabinetes foram classificados pela taxa de coalescência obtida e mostraram, comparativamente, muita variação - de 0,25 a 0,98, em uma escala de 0 a 1 .

A partir dessa classificação, foi possível constatar que o governo Itamar Franco mostrou-se altamente desviante do padrão encontrado nos outros três casos. Seu governo contou com 18 gabinetes, em média com uma coalescência de 0,5 e com duração baixa para os padrões observados nos outros casos. Chamou atenção, ainda, o fato de que Aécio é o governador com as menores taxas de coalescência ponderada. Os valores calculados para o seu governo não passam de 0,57. Os governos gaúchos, por sua vez, chamam atenção pela durabilidade dos gabinetes. Se a média desse indicador é comparada aos outros casos, o que se tem é um valor relativamente mais elevado.

Para testar as hipóteses sobre a relação entre os atributos das coalizões e os resultados legislativos obtidos pelo governo, foi modelada uma regressão logística binária que chegou, no seu melhor ajuste, a explicar 19\% da variância da variável dependente. Os resultados desse teste apontaram para a observação da hipóteses 1 do trabalho ("quanto mais coalescente uma coalizão de governo, menor será o volume de resultados de soma positiva"). No caso das hipóteses 2 e 3 ("quanto mais contígua uma coalizão de governo, menor será o volume de resultados de soma positiva" e "quanto maior o contingente legislativo de um governo, menor será o volume de resultados de soma positiva"), os valores do teste não permitem assegurar com confiabilidade razoável que esse seja uma explicação consistente. No entanto, a inclusão da variável contingente legislativo do partido do governador mostrou resultados não esperados. Quanto maior o contingente legislativo do partido do governador, maior a probabilidade de que se tenha um resultado de soma positiva.

Diante desses resultados, algumas questões permanecem abertas. Primeiro, para que o estudo apresentado esteja completo faz-se necessário comparar o relacionamento entre os poderes utilizando estados com diferentes graus de desenvolvimento institucional e subsistemas partidários. Se a observação do padrão decisório nos dois estados com valores altos nas duas dimensões é válida para mostrar que há variação frente ao que foi encontrado por Abrucio, mais interessante será comparar os padrões de governabilidade entre estados que apresentam estruturas diferentes.

Segundo, afirmar que os partidos são importantes para explicar o funcionamento de governos e comportamento de parlamentares no nível subnacional não autoriza ao pesquisador excluir a hipótese de que a cooptação parlamentar por parte do governador seja relevante. Se os dados sobre as emendas estaduais de parlamentares estivessem disponíveis ou organizadas nas assembleias pesquisadas por este trabalho, tal verificação teria sido realizada. Não estando, fica o registro da importância de conseguir-se isolar o efeito do padrão alocativo de emendas orçamentárias ou da execução de obras no estado sobre o apoio dado ao governo, ou o tipo de legislação produzida. Acreditase na possibilidade de se pensar em uma interpretação que combine o uso estratégico dos recursos à disposição do governador como principal fator para explicar o tipo de padrão decisório encontrado nos estados.

Terceiro e último apontamento, o tipo de dado utilizado neste trabalho permite que modelos hierárquicos sejam rodados para compreender-se os efeitos multivariados que os atributos dos deputados, de seus partidos, das coalizões e dos estados geram sobre o comportamento dos parlamentares. A união dessas bases proporcionaria a interação e a complexificação do entendimento da realidade aqui pesquisada. Talvez, mais do que contrapor a explicação que ressalta a importância dos partidos e dos líderes à explicação que reforça o papel da arena eleitoral na determinação 
do comportamento dos legisladores, seja importante examinar a combinação estratégica dessas arenas e a variedade de padrões que podem ser observados.

Felipe Nunes (felipenunes@ucla.edu) é Doutorando em Ciência Política pela Universidade da California, Los Angeles (UCLA).

\section{REFERÊNCIAS BIBLIOGRÁFICAS}

ABRUCIO, F. L. 1998. O ultrapresidencialismo estadual. In: ANDRADE, R. C. (org.). Processo de governo no município e no estado. São Paulo: EDUSP.

. 2002. Os barões da federação: os governadores e a redemocratização brasileira. $2^{\mathrm{a}}$ ed. São Paulo: Hucitec.

ABRUCIO, F. L.; TEIXEIRA, M. A. C. \& COSTA, V. M. F. 2001. O papel institucional da Assembléia Legislativa paulista: 1995 a 1998. In: SANTOS, F. (org.). O Poder Legislativo nos estados: diversidade e convergência. Rio de Janeiro: FGV.

ALEMAN, E. \& CALVO, E. 2007. Analyzing Legislative Success in Latin America: the case of democratic Argentina. Digit.

AMORIM NETO, O. 2000. Gabinetes presidenciais, ciclos eleitorais e disciplina legislativa no Brasil. Dados, Rio de Janeiro, v. 43, n. 2. Disponível em: http://www.scielo.br/scielo.php?pid=S0011$52582000000300003 \&$ script $=$ sci_arttext. Acesso em: 22.jul.2013.

2002. Presidential Cabinets, Electoral Cycles, and Coalition Discipline in Brazil. In: MORGENSTERN, S. \& NACIF, B. (eds.). Legislative Politics in Latin America. New York: University of Cambridge.

2007. Algumas conseqüências políticas de Lula: novos padrões de formação e recrutamento ministerial, controle de agenda e produção legislativa. In: NICOLAU, J. \& POWER, T. (orgs.). Instituições representativas no Brasil. Balanço e reforma. Belo Horizonte: UFMG.

AMORIM NETO, O.; COX, G. \& MCCUBBINS, M. 2003. Agenda Power in Brazil's Câmara dos Deputados, 1989-98. World Politics, Princeton, v. 55, n. 4, p. 550-578, July.

ANASTASIA, F. 2001. Transformando o Legislativo: a experiência da Assembléia Legislativa de Minas Gerais. In: SANTOS, F. (org.). O Poder Legislativo nos Estados: diversidade e convergência. Rio de Janeiro: FGV.
ANASTASIA, F. \& INÁCIO, M. 2008. Notas sobre coalizões políticas e democracia. In: MESSENBERG, D.; BARROS, F. L.; PINTO, J. R. S.; ASSIS, E. M. B.; MOURA, D. S. M. \& MENDES, L. V. A. (orgs.). Estudos Legislativos. Pensamento e ação política. Brasília, Câmara dos Deputados.

ANDRADE, R. C. 1998. Processo de governo no município e no estado. São Paulo: EDUSP.

BOND, J. \& FLEISHER, R. 1990. The President in the Legislative Arena. Chicago: University of Chicago.

CAMERON, C. M. 2000. Veto Bargaining: Presidents and the Politics of Negative. Cambridge (UK): University of Cambridge.

CAREY, J. 2000. Consequences of Institutional Design: term limits and budgetary procedures in presidential systems. In: VALADÉS, D. \& SERNA, J. M. (eds.). El gobierno en América Latina: presidencialismo o parlamentarismo? Ciudad del México: UNAM.

CAREY, J. \& SHUGART, M. 1998. Poder de decreto: chamando os tanques ou usando a caneta? Revista Brasileira de Ciências Sociais, São Paulo, v. 13, n. 37, jun. Disponível em: http:// www.scielo.br/scielo.php? pid=S 0102 69091998000200009\&script=sci_arttext. Acesso em: 22.jul.2013.

CASTRO, M. M. M.; ANASTASIA, F. \& NUNES, F. 2009. Determinantes do comportamento particularista de Legisladores estaduais brasileiros. Dados, Rio de Janeiro, v. 52, n. 4, p. 961-1001. Disponível em: http://www.scielo.br/pdf/dados/ v52n4/v52n4a05.pdf. Acesso em: 22.jul.2013.

CHEIBUB, J. A.; PRZEWORSKI, A. \& SAIEGH, S. 2004. Government Coalitions and Legislative Success Under Parliamentarism and Presidentialism. British Journal of Political Science, Cambridge (UK), v. 34, n. 4, p. 565-587, Sep. Disponível em: http://as.nyu.edu/docs/IO/2800/bjps_2004.pdf. Acesso em: 22.jul.2013.

COHEN, L. R. \& NOLL, R. G. 1991. How to Vote, Whether to Vote: strategies for voting and abstaining 
on congressional roll calls. Political Behavior, New York, v. 13, n. 2, p. 97-127, June.

COUTO, C. G. 1998. Negociação, decisão e governo: padrões de interativos na relação ExecutivoLegislativo e o caso paulistano. In: ANDRADE, R. C. (org.). Processo de governo no município e no estado. São Paulo: EDUSP.

COX, G. \& MCCUBBINS, M. 1993. Legislative Leviathan: party government in the House. Berkeley: University of California.

2005. Setting the Agenda: responsible party government in the U.S. House of Representatives. New York: University of Cambridge.

FIGUEIREDO, A. \& LIMONGI, F. 1999. Executivo e Legislativo na Nova Ordem Constitucional. Rio de Janeiro: FGV.

GARSON, G. D. Logistic Regression. In: Statnotes: topics in multivariate analysis. Disponível em: http://www.statisticalassociates.com/. Acesso em: 22.jul.2013.

GROSECLOSE, T. \& MCCARTY, N. 2001. The Politics of Blame: bargaining before an audience. American Journal of Political Science, Bloomington, v. 45, n. 1, p. 100-119, Jan.

INACIO, M. 2006. Presidencialismo de coalizão e sucesso presidencial na esfera legislativa 19902004. Belo Horizonte. Tese (Doutorado em Ciência Política). Universidade Federal de Minas Gerais.

JONES, C. 1994. The Presidency in a Separated System. Washington (DC): Brookings.

LIMA JR, O. B. 1984. Os partidos políticos brasileiros: a experiência federal e regional, 1945-1964. Rio de Janeiro: Graal.

(org.). 1997. O sistema partidário brasileiro. Diversidade e Tendências. 1982-1994. Rio de Janeiro: FGV.

LIMONGI, F. 1994. O novo institucionalismo e os estudos legislativos: a literatura norte-americana recente. $B I B$, Rio de Janeiro, n. 37, p. 3-38. Disponível em: http://www.fflch.usp.br/dcp/assets/ docs/Limongi/O_Novo_Institucionalismo _e_os_Estudos_Legislativos.pdf. Acesso em: 22.jul.2013.

2006a. Presidencialismo e governos de coalizão. In: AVRITZER, L. \& ANASTASIA, F. (orgs.). Reforma política no Brasil. Belo Horizonte: UFMG.

LIMONGI, F. \& FIGUEIREDO, A. 1994. O processo legislativo e a produção legal no Congresso Pós-
Constituinte. Novos Estudos, São Paulo, v. 38, p. 3-38.

MAINWARING， S. 1993. Presidentialism, Multipartism, and Democracy: the difficult combination. Comparative Political Studies, Thousand Oaks, v. 26, n. 2 , p. 198-228.

MAIR, P. 2006. Political Parties and Party Systems. In: GRAZIANO, P. \& VINK, M. (eds.). Europeanization: new research agendas. Basingstoke: Palgrave Macmillan.

MELO, C. R. \& NUNES, F. 2008. Ideologia e distância de preferências: uma comparação dos governos Lagos e Lula. No prelo.

MUELLER, W. \& STROM, K. 2000. Policy, Office, or Votes: how political parties in Western Europe make hard decisions. Cambridge: University of Cambridge.

NEUSTADT, R. E. 1960. Presidential Power. The politics of leadership. New York: Wiley.

NICOLAU, J. 2000. Disciplina partidária e base parlamentar na Câmara dos Deputados no primeiro governo Fernando Henrique Cardoso (1995-1998). Dados, Rio de Janeiro, v. 43, n. 4. Disponível em: http://www.scielo.br/scielo.php?script= sci_arttext\&pid=S0011-52582000000400004. Acesso em: 1.ago.2013.

NUNES, Felipe. (2012) What is the Best Strategy to Obtain Legislative Support? Survey Evidence from Brazilian State Assemblies. Brazilian Political Science Review, v. 6, n 2.

2009b. Governos de coalizão e resultados de soma positiva em Minas Gerais e no Rio Grande do Sul, 1999-2006. Dissertação (Mestrado em Ciência Política). Universidade Federal de Minas Gerais.

2011. Coalizões legislativas estaduais: uma análise comparativa dos governos de Minas Gerais e Rio Grande do Sul entre 1998-2006. Teoria \& Sociedade, Belo Horizonte, v. 19, n. 2.

PETERSON, M. 1993. Legislating Together: The White House and Capitol Hill from Eisenhower to Reagan. Cambridge (MA): Harvard University.

POWER, T. \& ZUCCO, C. 2009. Estimating Ideology of Brazilian Legislative Parties, 19902005: a research communication. Pittsburgh: LARR. No prelo.

RIKER, W. 1962. The Theory of Political Coalitions. New Haven: Yale University.

ROSE, R. 1984. Electoral Systems: a question of 
degree or of principle? In: LIJPHART, A. \& GROFMAN, B. (eds.). Choosing an Electoral System: issues and alternatives. New York: Praeger.

SAIEGH, S. 2004. Government Defeat: coalitions, responsiveness, and legislative success. New York. Tese (Doutorado em Ciência Política). New York University.

SANTOS, F. 1997. Patronagem e poder de agenda na política brasileira. Dados, Rio de Janeiro, v. 40, n. 3, p. 465-491. Disponível em: http:/www.scielo.br/ scielo.php?pid=S0011-52581997000300007 \&script=sci_arttext. Acesso em: 17.jul.2013. (org.). 2001. O Poder Legislativo nos Estados: diversidade e convergência. Rio de Janeiro: FGV. 2003. O Poder Legislativo no presidencialismo de coalizão. Belo Horizonte: UFMG.

SARTORI, G. 1994. A teoria da democracia revisitada. V. 1, “O debate contemporâneo". São Paulo: Ática.

SCHUGART, M. \& CAREY, J. 1992. Presidents and Assemblies. Cambridge (UK): University of Cambridge. 


\section{THE DETERMINANTS OF POSITIVE-SUM OUTCOMES IN THE BRAZILIAN STATE ASSEMBLIES} OF MINAS GERAIS AND RIO GRANDE DO SUL.

\section{Felipe Nunes.}

Legislative studies emphasize greatly the result that governments get to approve or not their agenda. In this article I propose a new way of understanding legislative success. More than the result itself, I argue that governments care about the repercussions about what they do to the electorate. After classifying the way legislative results were obtained in the Legislative Assemblies of Minas Gerais and Rio Grande do Sul from 1999 to 2006, I analyze potential factors that explain the variation in the level of positive-sum outcomes identified in each legislature. I focus particularly on the composition and size of government coalitions in the two states. My main finding is that the more coalescing of a coalition government, the smaller tends to be the volume of positive-sum outcomes. The premise for understanding this result is that the more distant are the preferences of the executive and the party with which they are negotiating, the greater tends to be trading for positions in exchange for approval of the policy preferred by the government. It seems plausible, therefore, that the distribution of positions in departments coalescing only happens when the parties in negotiation do not agree with the proposed agenda. In this context, thus, decisions with lower degree of consensus among actors in competition will be sent by the Executive to the Legislative proceedings. Thus, it is expected that positive-sum decisions to be less recurrent.

KEYWORDS: State legislatures; State executives; Legislative success; Government coalitions; Coalition presidentialism; positive-sum. 